\title{
Modulation of TARP $\gamma 8$-Containing AMPA Receptors as a Novel Therapeutic Approach for Chronic Pain ${ }^{\llbracket}$
}

\author{
Kelly L. Knopp, Rosa Maria A. Simmons, Wenhong Guo, Benjamin L. Adams, \\ Kevin M. Gardinier, ${ }^{2}$ Douglas L. Gernert, Paul L. Ornstein, ${ }^{3}$ Warren Porter, Jon Reel, \\ Chunjin Ding, He Wang, Yuewei Qian, Kevin D. Burris, Anne Need, Vanessa Barth, \\ Steven Swanson, John Catlow, Jeffrey M. Witkin, Ruud Zwart, Emanuele Sher, \\ Kar-Chan Choong, Theron M. Wall, Douglas Schober, Christian C. Felder, \\ ๑1 Akihiko S. Kato, @David S. Bredt, ${ }^{4}$ and Eric S. Nisenbaum ${ }^{1}$
}

Lilly Research Laboratories, Eli Lilly and Company, Indianapolis, Indiana (K.L.K., R.M.A.S., W.G., B.L.A., K.M.G., D.L.G., P.L.O., W.P., J.R., C.D., H.W., Y.Q., K.D.B., A.N., V.B., S.S., J.C., J.M.W., K.-C.C., T.M.W., D.S., C.C.F., A.S.K., D.S.B., E.S.N.) and Lilly Research Centre, Eli Lilly and Company Ltd., Erl Wood Manor, Windlesham, Surrey, United Kingdom (R.Z., E.S.)

Received July 16, 2018; accepted March 6, 2019

\section{ABSTRACT}

Nonselective glutamate $\alpha$-amino-3-hydroxy-5-methyl-4isoxazolepropionic acid (AMPA) receptor antagonists are efficacious in chronic pain but have significant tolerability issues, likely arising from the ubiquitous expression of AMPA receptors in the central nervous system (CNS). Recently, LY3130481 has been shown to selectively block AMPA receptors coassembled with the auxiliary protein, transmembrane AMPA receptor regulatory protein (TARP) $\gamma 8$, which is highly expressed in the hippocampus but also in pain pathways, including anterior cingulate (ACC) and somatosensory cortices and the spinal cord, suggesting that selective blockade of $\gamma 8 /$ AMPA receptors may suppress nociceptive signaling with fewer CNS side effects. The potency of LY3130481 on recombinant $\gamma 8$-containing AMPA receptors was modulated by coexpression with other TARPs; $\gamma 2$ subunits affected activity more than $\gamma 3$ subunits. Consistent with these findings, LY3130481 had decreasing potency on receptors from rat hippocampal, cortical, spinal cord, and cerebellar neurons that was replicated in tissue from human brain. LY3130481 partially suppressed, whereas the nonselective AMPA antagonist GYKI53784 completely blocked, AMPA receptor-dependent excitatory postsynaptic potentials in ACC and spinal neurons in vitro. Similarly, LY3130481 attenuated short-term synaptic plasticity in spinal sensory neurons in vivo in response to stimulation of peripheral afferents. LY3130481 also significantly reduced nocifensive behaviors after intraplantar formalin that was correlated with occupancy of CNS $\gamma 8$-containing AMPA receptors. In addition, LY3130481 dose-dependently attenuated established gait impairment after joint damage and tactile allodynia after spinal nerve ligation, all in the absence of motor side effects. Collectively, these data demonstrate that LY3130481 can suppress excitatory synaptic transmission and plasticity in pain pathways containing $\gamma 8$ /AMPA receptors and significantly reduce nocifensive behaviors, suggesting a novel, effective, and safer therapy for chronic pain conditions.

\section{Introduction}

Although the etiology of chronic pain is diverse (e.g., tissue injury, inflammation), a long-term sensitization of the central somatosensory pathways is common to many disorders and is

Dr. K.L.K. reports financial support (salaries) for all authors from Eli Lilly \& Company, outside the submitted work.

On September 26, 2016, Cerecor Inc. announced the acquisition of LY3130481 (now CERC-611) from Eli Lilly \& Co. for development in patients with epilepsy. In addition, a patent WO 2015183673 A1 has been issued to Eli Lilly \& Company for the molecule.

Primary laboratory of origin: Lilly Research Laboratories, Eli Lilly and Company, Indianapolis, IN 46285.

${ }^{1}$ Current affiliation: CNS Discovery Research, Alkermes Inc., Waltham, Massachusetts.

${ }^{2}$ Current affiliation: Global Discovery Chemistry, Novartis Institutes for BioMedical Research, Cambridge, Massachusetts.

${ }^{3}$ Current affiliation: Medicinal Chemistry School of Pharmacy Medical College of Wisconsin, Milwaukee, Wisconsin.

${ }^{4}$ Current affiliation: Neuroscience Discovery, Janssen Pharmaceutical Companies of Johnson \& Johnson, San Diego, California.

https://doi.org/10.1124/jpet.118.250126.

[S This article has supplemental material available at jpet.aspetjournals.org. characterized by increased neuronal excitability and enhanced synaptic transmission in nociceptive and non-nociceptive pathways that underlies the hallmark symptoms of allodynia, hyperalgesia, and spontaneous pain (Latremoliere and Woolf, 2009). While multiple mechanisms contribute to central sensitization, the release of glutamate from peripheral nerve terminals, activation of ionotropic glutamate $\alpha$-amino-3hydroxy-5-methyl-4-isoxazolepropionic acid (AMPA) receptors, and subsequent recruitment of $N$-methyl-D-aspartate (NMDA) receptor activity in the dorsal horn of the spinal cord are critical for the initiation and maintenance of enhanced synaptic transmission in central pain pathways (Davies and Lodge, 1987; Yoshimura and Jessell, 1990; Woolf and Thompson, 1991). Consistent with the role of AMPA receptors in central sensitization, clinical studies have demonstrated that compounds with AMPA receptor antagonist properties (e.g., tezampanel, topiramate, NS1209) can attenuate the symptoms of chronic pain but are accompanied by significant tolerability issues (e.g., dizziness, 
sedation) (Wandschneider et al., 2017), probably due to the ubiquitous expression of AMPA receptors in the central nervous system (CNS) (Olsen et al., 1987). This hypothesis is supported by preclinical studies which have demonstrated that nonselective AMPA receptor antagonists reduce nocifensive behaviors at doses that also produce motor side effects and sedation (Simmons et al., 1998; Nishiyama et al., 1999).

AMPA receptors mediate the majority of fast excitatory transmission in the CNS and are tetramers composed of one or more GluA1-4 subunits that can have two alternative splice variants (flip and flop) (Sommer et al., 1990; Monyer et al., 1991). Additional diversity is conferred by association with auxiliary subunits termed transmembrane AMPA receptor regulatory proteins (TARPs; $\gamma 2, \gamma 3, \gamma 4, \gamma 5, \gamma 7$, and $\gamma 8$ ) and cornichon proteins (CNIH-2, CNIH-3) that are heterogeneously expressed in the CNS and can influence channel kinetics, receptor trafficking, and pharmacology (Schwenk et al., 2009, 2012; Jackson and Nicoll, 2011). Of the TARPs, $\gamma 8$ has the highest expression in the hippocampus, but appreciable expression is also observed in regions associated with nociceptive processing, including the anterior cingulate (ACC) and somatosensory (SS) cortices, sensory thalamus, and dorsal horn of the spinal cord (Tomita et al., 2003; Fukaya et al., 2006; Inamura et al., 2006; Menuz et al., 2009; Larsson et al., 2013). In these nociceptive regions, $\gamma 2$ and $\gamma 3$ TARPs are also expressed at relatively high levels (Tomita et al., 2003). Ultrastructural analyses have demonstrated that $\gamma 2$ and $\gamma 8$ subunits are localized to postsynaptic densities of presumptive excitatory synapses in the cortex (Inamura et al., 2006), whereas $\gamma 2, \gamma 3, \gamma 4, \gamma 7$, and $\gamma 8$ TARPs are expressed in the spinal cord and $\gamma 8$ is highly expressed at postsynaptic sites from primary afferents onto dorsal horn neurons (Larsson et al., 2013; Sullivan et al., 2017). Collectively, these data suggest that $\gamma 8$-containing AMPA receptors may be important for establishing the activity-dependent sensitization of glutamatergic nociceptive inputs in spinal and supraspinal regions of the CNS.

Recently, a novel AMPA receptor antagonist, LY3130481, has been identified which selectively blocks TARP 78-containing AMPA receptors (Gardinier et al., 2016; Kato and Witkin, 2018). LY3130481 displays nanomolar potency for blockade of recombinant and native $\gamma 8$-containing AMPA receptors and $\geq 100$-fold selectivity versus AMPA receptors associated with other $\gamma$ subunits or GluA subunits alone (Gardinier et al., 2016; Kato et al., 2016). The compound also has pharmacokinetic properties suitable for testing in vivo, including high oral bioavailability, modest intrinsic clearance, and high CNS exposure (Gardinier et al., 2016; Kato et al., 2016). The present studies used LY3130481 to interrogate the hypothesis that selective blockade of $\gamma 8$-containing AMPA receptors can reduce glutamatergic synaptic transmission in CNS somatosensory pathways and attenuate nocifensive responses in animal models of hyperexcitable neurotransmission with reduced CNS side effects.

\section{Materials and Methods}

\section{Experimental Animals}

All animal studies were reviewed and approved by the Lilly Institutional Animal Care and Use Committee and conformed to the guidelines provided by the National Institutes of Health and the International Association for the Study of Pain. Animals were randomly assigned to treatment groups, and experimenters performing behavioral scoring were blinded to treatment (drug or genotype) assignment. The same experimenter performed all studies for a given assay.

Depending on body weight, rats were either group housed or pair housed in large, high-density, plexiglass cages with bedding and enrichment. Mice were group housed in high-density, large, plexiglass mouse cages with bedding and enrichment. Animals were maintained in temperature- and humidity-controlled rooms on a 12-/12-hour light/dark cycle (lights on at 6 a.m.) and given ad libitum access to food and water unless otherwise specified. All behavioral testing was conducted between 7:30 a.m. and 4 p.m. during the light cycle. The testing room temperature was maintained at $21^{\circ} \mathrm{C}-23^{\circ} \mathrm{C}$.

\section{Formalin Assay}

Male Sprague-Dawley (SD) rats (186-240 g) were used for the rat formalin assay (Charles River, Portage, MI). CD-1 Icr mice (32-43 g; Harlan, Indianapolis, IN) were used for the mouse formalin studies. For the transgenic studies, mice were generated at Taconic (Cambridge City, IN) on a CD-1 background, weighing 24-37 g at the time of testing. The $\gamma 8^{+/+}$and $\gamma 8^{-/-}$mice were age matched. The formalin assay was performed in custom-made plexiglass boxes, $22 \times$ $22 \times 20 \mathrm{~cm}$ for rats and $12.5 \times 12.5 \times 12.5 \mathrm{~cm}$ for mice. A mirror placed at the back of the cage allowed the unhindered observation of the formalin-injected paw. Rats were habituated to the chambers for at least 30 minutes prior to the experiment, and mice were habituated for 60 minutes. LY3130481 was administered by mouth (PO) 30 minutes before the formaline challenge, tramadol was administered PO 1 hour before, and carbamazepine was administered i.p. 30 minutes before. A $5 \%$ formalin solution in $0.9 \%$ saline (injection volume of $50 \mu \mathrm{l}$ for rats and $20 \mu \mathrm{l}$ for mice) was injected subcutaneously into the dorsal lateral surface of one hind paw with a 27 -gauge needle for rats and into the plantar surface of one hind paw for mice. Real-time observation began immediately after the formalin injection. Formalin-induced nocifensive responding was quantified by recording the number of seconds of each licking/biting event, binned in 5-minute intervals for 60 minutes after the formalin injection. Two phases of pain behavior were observed as previously described (Wheeler-Aceto et al., 1990). The early phase started immediately after the formalin injection and lasted approximately 5 minutes, followed by the late phase that started between minutes 10 and 15 with a maximal response typically observed around 25-35 minutes after the formalin injection. After the 60-minute observation period, animals were sacrificed with $\mathrm{CO}_{2}$ followed by cervical dislocation as a secondary measure.

The total time spent licking and biting the injected paw (Coderre et al., 1993; Abbott et al., 1995) was recorded; the early phase score was the sum of time spent licking in seconds from 0 to 5 minutes, and the late phase score was obtained by adding the total number of seconds spent licking from minute 16 to minute 40 of the observation period for rats and minute 16 to minute 55 for mice. Data are presented as means \pm S.E.M. and were evaluated by one-way analysis of variance (ANOVA), and the appropriate contrasts were analyzed by Dunnett's $t$ test for two-sided comparisons. Differences were considered to be significant if the $P$ value was less than 0.05 .

ABBREVIATIONS: ACC, anterior cingulate cortex; aCSF, artificial cerebrospinal fluid; AMPA, $\alpha$-amino-3-hydroxy-5-methyl-4-isoxazolepropionic acid; APV, (2R)-amino-5-phosphonovaleric acid; CFA, complete Freund's adjuvant; CNS, central nervous system; CTZ, cyclothiazide; EPSP, excitatory postsynaptic potential; mw, molecular weight; NMDA, $\mathrm{N}$-methyl-D-aspartate; PO, per os; qPCR, quantitative polymerase chain reaction; SD, Sprague-Dawley; SNL, spinal nerve ligation; SS, somatosensory; TARP, transmembrane AMPA receptor regulatory protein; WDR, wide dynamic range. 


\section{Gait Assay}

Female SD rats (200-240 g; Harlan) were used for the gait study. Rats were anesthetized with $4 \%$ isoflurane in oxygen, and the rear right knee was shaved and sterilized with $70 \%$ ethanol. Injections were performed with a 27-gauge needle fitted with PE10 tubing (Intramedic) such that $4 \mathrm{~mm}$ of the needle tip was exposed, thereby controlling injection depth. Complete Freund's adjuvant (CFA; $1 \mathrm{mg} / \mathrm{ml}$ concentration, catalog number F-5881, lot number 101k8927; Sigma-Aldrich, St. Louis, MO) was diluted with Freund's incomplete adjuvant (catalog number 642861, lot number 07263; MP Biomedicals LLC) to form a $0.4-\mathrm{mg} / \mathrm{ml}$ suspension. Each rat received $20 \mu \mathrm{g}$ of CFA in a $50-\mu \mathrm{l}$ injection.

The GaitScan (CleverSys Inc., Reston, VA) gait analysis system recorded and quantified gait features, and the experimental procedure was conducted as previously described (Adams et al., 2016). In brief, the system consisted of a clear treadmill (ExerGait XL; Columbus Instruments, Columbus, $\mathrm{OH}$ ) fitted with an angled mirror underneath. A high-speed camera (100 frames per second; Basler) recorded the ventral view of a moving rat. An opaque green plexiglass box with a semitransparent viewing window was positioned above the treadmill to house the animal. Video was captured by the BCam software program for 2000 frames per animal for analysis. This color-based tracking system allowed maximal tracking of the paw while excluding other body parts or shadows. Filters were applied to enable the analysis of multiple steps per animal. An a priori inclusion criterion of a minimum of three strides per rear limb was required for all studies.

Prior to CFA administration, rats were habituated to the treadmill for 60 seconds. The treadmill was slowly increased from 0 to $2 \mathrm{~cm} / \mathrm{s}$. After the animal moved forward and away from the back wall twice, the speed was slowly increased to $4 \mathrm{~cm} / \mathrm{s}$. Infrequently, a cotton swab was inserted into the front of the treadmill to reorient a rat that was excessively rearing or exploring the chamber, effectively returning the rat to a normal walking pattern. In addition, a rounded "bumper" was placed on the back wall to minimize any negative impact of contact while the rat was learning the forced-ambulation paradigm. Once the animal walked consistently, trial speeds were increased in increments of 2 to $3 \mathrm{~cm} / \mathrm{s}$ until the animal successfully ran at or near $16 \mathrm{~cm} / \mathrm{s}$. The animal was then placed back in the home cage.

Rats received a baseline gait session the day after CFA administration (day 2). The next day, rats were randomly assigned to groups and received one of the following treatments 60 minutes prior to the test session: vehicle; $1,3,10$, or $30 \mathrm{mg} / \mathrm{kg} \mathrm{LY} 3130481$; or $40 \mathrm{mg} / \mathrm{kg}$ tramadol $\mathrm{HCl}(4 \mathrm{ml} / \mathrm{kg})$. All compounds were orally administered at $10 \mathrm{ml} / \mathrm{kg}$. For the baseline and test sessions, the treadmill speeds were slowly ramped from 0 to the target speed of $12-16 \mathrm{~cm} / \mathrm{s}$, depending on the ability of the individual rat. Filters in the analysis software were implemented to exclude instances of pausing, rearing, turning, or riding back, or when the rat was touching the rear of the treadmill, thereby decreasing the variability in gait measures and allowing a more accurate representation of locomotion.

\section{Spinal Nerve Ligation Assay}

Male Sprague-Dawley rats (Harlan) weighing 150-200 g at the time of surgery were acclimated for at least 4 days prior to surgery. Surgery was performed on day 0 as described previously (Kim and Chung, 1992). In brief, rats were placed under gas anesthesia using a mixture of isoflurane (3\% for induction, $2 \%$ for maintenance) and oxygen. Rats were placed in a prone position, and the left paraspinal muscles were separated from the spinous processes at the L4-S2 levels. The L6 transverse process was carefully removed with a small rongeur to identify visually the L4-L6 spinal nerves. The left L5 and L6 spinal nerves were isolated and tightly ligated with 6-0 silk thread, and the L4 spinal nerve was lightly tapped (up to 20 times) with a glass rod to produce adequate nerve injury. The muscle was then closed with 3-0 silk sutures, and wound clips were used to close superficial skin. After surgery, rats were returned to their home cages. As the surgery was conducted at Covance Laboratories (Greenfield, IN), the rats were shipped to Lilly Research Laboratories the day after surgery (day 1). A total of 33 rats underwent spinal nerve ligation (SNL) surgery. On postoperative days $1,3,5$, and 7 , and weekly thereafter, the rat's left hind paw was lightly tapped/brushed with an innocuous mechanical stimuli to prime the onset of hypersensitivity, as previously described (Simmons et al., 2014). After priming, baseline hypersensitivity was evaluated using the up-down method of paw withdrawal in response to von Frey filaments with incremental bending forces $(0.3-15 \mathrm{~g})$ as previously described (Chaplan et al., 1994). Any rat that did not reach the predetermined inclusion criterion of a baseline response of $<2 \mathrm{~g}$ in the paw ipsilateral to the ligation was not included in the drug study. Treatment assignment was block randomized based on body weight. During the drug study, beginning 31 days after nerve ligation surgery, rats were place in elevated observation chambers with wire mesh floors and allowed an acclimation period of 10-20 minutes before testing. Rats were administered vehicle, LY3130481, or the positive control gabapentin PO, and tactile hypersensitivity was evaluated $0.5,1$, and 1.5 hours after administration. Dosing was continued for 4 more days, and hypersensitivity was again evaluated at 0.5 and 1 hour postadministration. All behavioral studies were conducted by a blinded observer. Data are expressed as the threshold force required to elicit a response (grams) and are expressed as means \pm S.E.M. Statistical analysis was performed using JMP 8.0 software (SAS Institute Inc., Cary, NC), and data were evaluated by one-way ANOVA and the appropriate contrasts analyzed by Dunnett's $t$ test for two-sided comparisons. Values of $P<0.05$ were considered statistically significant.

\section{Drug Treatments for In Vivo Studies}

LY3130481 was prepared at $3 \mathrm{mg} / \mathrm{ml}$ for rats and at 0.5 or $1 \mathrm{mg} / \mathrm{ml}$ for mice by dissolving the compound in dimethylsulfoxide (5\% of total volume), adding $10 \%$ Acacia and $0.05 \%$ antifoam (Fisher Scientific), and vortexing until solubilized for the formalin, rotorod, and gait assays. The compound was serially diluted if needed and dosed at $10 \mathrm{ml} / \mathrm{kg}$. For in vivo electrophysiological studies, LY3130481 was dissolved in 20\% Captisol (CyDex) in water and sonicated for 45 minutes in a warm-water bath.

GYKI52466 was synthesized at Eli Lilly. For the formalin and rotorod studies, GYKI52466 was prepared at $3 \mathrm{mg} / \mathrm{ml}$ in milliQ water and bath sonicated until solubilized. The compound was serially diluted if needed and dosed at $10 \mathrm{ml} / \mathrm{kg}$ i.p. For in vivo electrophysiological studies, GYKI52466 was dissolved in $0.9 \%$ saline and sonicated for 30 minutes in a warm bath prior to intravenous administration via the jugular vein.

Tramadol HCl (Teva Pharmaceuticals) was prepared by sonicating crushed tablets in a $1 \%$ hydroxyethylcellulose (HEC), $0.25 \%$ Tween 80 , and $0.05 \%$ Dow antifoam for the gait study and in MilliQ water for the rat formalin study to form a suspension with the assumption that each tablet contained $50 \mathrm{mg}$ of active drug. Rats were dosed $40 \mathrm{mg} / \mathrm{kg}$ (PO) in a dose volume of $4 \mathrm{ml} / \mathrm{kg}$. Pretreatment times were 1 hour prior to testing in the formalin and gait assays.

Gabapentin (Neurontin, 400-mg capsules) was purchased from Capital Wholesale Drug Co. (Columbus, OH). A 12.5-mg/ml suspension of gabapentin was prepared by dissolving the contents of a $400-\mathrm{mg}$ Neurontin capsule in $32 \mathrm{ml}$ of vehicle [Milli-Q (Millipore) water] and dosed at $75 \mathrm{mg} / \mathrm{kg}$.

All drugs used for in vivo studies were prepared fresh daily.

\section{Pharmacokinetics}

Male SD rats (Harlan) weighing 250-270 g were fasted for at least 12 hours and dosed PO with LY3130481 (3 mg/kg in a 10-ml/kg dose volume) or $1 \mathrm{mg} / \mathrm{kg}$ i.v. in a $1-\mathrm{ml} / \mathrm{kg}$ dose volume. The vehicle solutions for oral and intravenous delivery were Acacia, antifoam, and propylene glycol or polyethylene glycol $40080 \%(\mathrm{v} / \mathrm{v})$ and $N$-methylpyrrolidone $20 \%(\mathrm{v} / \mathrm{v})$, respectively. Plasma samples $(75-250 \mu \mathrm{l})$ were collected via cannulation of the femoral artery at time points of $0,0.08,0.25,0.5,1$, $2,3,8,12$, and 24 hours post dosing. Samples were placed into vials 
containing EDTA on ice, centrifuged, and stored at $\leq-20^{\circ} \mathrm{C}$ for later high-performance liquid chromatography analysis.

\section{Receptor Occupancy}

Male SD rats (200-240 g; Harlan) were used for the receptor occupancy studies. Food and water were provided ad libitum, but food was removed approximately 12 hours prior to $\mathrm{PO}$ administration. Rats ( $n=3$ to 4$)$ were administered either vehicle alone (10\% Acacia with $0.05 \%$ antifoam in purified water) or LY3130481 $(0.1-30 \mathrm{mg} / \mathrm{kg})$ via oral gavage in a dose volume of $10 \mathrm{ml} / \mathrm{kg}$. Thirty minutes after receiving vehicle or compound, they received intravenous administration of nonlabeled tracer (LY3075449, $3 \mu \mathrm{g} / \mathrm{kg}$ in $25 \%$ hydroxypropyl$\beta$-cyclodextran, $0.5-\mathrm{ml} / \mathrm{kg}$ dose volume) in the lateral tail vein. Rats were sacrificed by cervical dislocation 40 minutes after nonlabeled tracer administration. Brains were removed, and the hippocampus and cerebellum were dissected, weighed, and placed in conical centrifuge tubes on ice. The remaining brain and plasma were provided for compound exposure analyses.

Four volumes (w/v) of acetonitrile containing $0.1 \%$ formic acid was added to each tube containing hippocampal or cerebellar tissue. Samples were then homogenized using an ultrasonic probe and centrifuged using a benchtop centrifuge at 14,000 rpm for 20 minutes. Supernatant was diluted with sterile water and analyzed for nonlabeled tracer concentration using liquid chromatography-tandem mass spectrometry. Standards were prepared by adding known quantities of the nonlabeled tracer to brain tissue samples from nontreated rats and processing as described earlier.

Receptor occupancy was calculated using the ratio method (Chernet et al., 2005; Barth et al., 2006) using the following equation:

$$
100 *\left\{1-\left[\left(\text { ratio }_{\mathrm{t}}-1\right) /\left(\text { ratio }_{\mathrm{c}}-1\right)\right]\right\}=\% \text { occupancy }
$$

Ratio refers to the ratio of nonlabeled tracer concentration measured in the hippocampus (total binding region) to the nonlabeled tracer concentration measured in the cerebellum (null binding region). Ratio ${ }_{t}$ is the ratio determined in each animal treated with LY3130481, and ratio $_{c}$ is the average ratio in the vehicle-treated animals.

\section{Quantitative Polymerase Chain Reaction}

Quantitative polymerase chain reaction (qPCR) measured expression of TARPs, also known as calcium channel auxiliary $\gamma$ subunits, Cacng2 (TARP $\gamma 2$ ), Cacng3 (TARP $\gamma 3$ ), Cacng8 (TARP $\gamma 8$ ), and Gria1 (GluA1), at mRNA levels in the cerebellum, lumbar of spinal cord, frontal cortex, and hippocampus from male SD rats weighing 230-240 g and male CD-1 mice weighing $25-40 \mathrm{~g}$. Total RNA was isolated from rat or mouse tissues using TRIzol reagent (Thermo Fisher Scientific/Invitrogen, Lenexa, KS). The isolated RNA was reversely converted to cDNA using a SuperScript III kit (Thermo Fisher Scientific). In brief, $2 \mu \mathrm{l}$ of total RNA $(250 \mathrm{ng} / \mu \mathrm{l})$ was mixed with $10 \mu \mathrm{l}$ of $2 \times$ reaction mix, $2 \mu \mathrm{l}$ of room temperature enzyme, and $6 \mu \mathrm{l}$ of nuclease-free water. The reverse transcription reaction was conducted at $25^{\circ} \mathrm{C}$ for 10 minutes followed by $50^{\circ} \mathrm{C}$ for 30 minutes and $85^{\circ} \mathrm{C}$ for 5 minutes. After chilling on ice, $1 \mu \mathrm{l}$ of RNase $\mathrm{H}$ was added into each reaction, and the mixture was incubated at $37^{\circ} \mathrm{C}$ for 20 minutes. The cDNA was diluted four times with nucleasefree water. The qPCR reaction was performed by mixing $2.5 \mu \mathrm{l}$ of diluted cDNA with $2 \mu \mathrm{l}$ of nuclease-free water, $5 \mu \mathrm{l}$ of TaqMan gene expression master mix (Thermo Fisher Scientific/Applied Biosystems, Lenexa, KS), and $0.5 \mu \mathrm{l}$ of qPCR primer/probe mix of each gene [rat hypoxanthine phosphoribosyltransferase 1 (Hprt1), Rn01527840; rat Cacng2, Rn00584355; rat Cacng3, Rn00589900; rat Cacng8, Rn00589915; rat Gria1, Rn00709588; mouse Hprt1, Mm00446968; mouse Cacng2, Mm00432248; mouse Cacng3, Mm00517091; mouse Cacng8, Mm00519222; mouse Gria1, Mm00433753; Thermo Fisher Scientific/Applied Biosystems]. Data for each of the genes were replicated three times. The $\mathrm{qPCR}$ reaction was conducted with QuantStudio 7 Flex (Applied Biosystems) with a preset relative qPCR program.
The Ct value was calculated with a fixed threshold at 0.2 for all targets. $\Delta \mathrm{Ct}$ was calculated as $\Delta \mathrm{Ct}=\mathrm{Ct}_{\text {gene }}-\mathrm{Ct}_{\mathrm{Hprt} 1}$. The data in graphs are normalized values by Hprt1 expression, and shown as $\Delta \Delta \mathrm{Ct}\left[\Delta \Delta \mathrm{Ct}=\Delta \mathrm{Ct}_{\text {gene }}-\Delta \mathrm{Ct}_{\text {normalizer }(\mathrm{Hprt} 1)}\right]$.

\section{In Vitro Electrophysiology}

Transfected Cell Preparation. The experimental procedure follows a previous report (Farkas and Ono, 1995). In brief, human cDNAs encoding the flip-splice variant of GluA1 AMPA receptor principal subunits (GluA1i; $160 \mathrm{ng}$ ), TARP/CNIH-2 auxiliary subunits (40 ng), and a green fluorescent protein (GFP) GFP (800 ng) driven by cytomegalovirus promoter were mixed and then incubated for 20 minutes with $100 \mu$ l of Dulbecco's modified Eagle's medium without serum or antibiotics containing $3 \mu \mathrm{l}$ of Fugene 6 (Promega Biosciences, Madison, WI) for 25 minutes at room temperature. The plasmid DNA-Fugene 6 complex was added onto HEK293T $\left(1 \times 10^{6}\right.$ cells/35 mm dish) cultured in Dulbecco's modified Eagle's medium + fetal bovine serum $(10 \%)+$ penicillin/streptomycin $(10 \mathrm{U} / \mathrm{ml})$. When introducing multiple auxiliary subunit cDNAs into the cells at various ratios, we kept the total amount of the auxiliary subunit cDNAs at $40 \mathrm{ng}$. The cells were trypsinized 1 day after transfection and seeded on coverslips at 1:30 dilution to keep the cell density sparse enough to pick up single cells for the patch-clamp electrophysiological recordings, which were performed after overnight incubation. To reduce the cytotoxicity by the AMPA receptor/auxiliary subunit expression, transfectants were cultured with 2,3-Dioxo-6nitro-1,2,3,4-tetrahydrobenzo[f]quinoxaline-7-sulfonamide (NBQX) $(20 \mu \mathrm{M})$ until recording. Also, the transfection marker, a GFPexpressing plasmid, was added at a high ratio $(80 \%$ weight of transfected DNA) compared with AMPA receptor/auxiliary subunit cDNAs.

Acutely Isolated Neuronal Preparations. This procedure was as previously described (Kato et al., 2016). In brief, neurons were acutely isolated from cortical (ACC and SS), hippocampal, cerebellar, or spinal cord (dorsal half) taken from SD rats, CD-1, or CD-1 congenic $\gamma 8^{-/-}$mice (2 to 3 weeks postnatal). Tissue slices including the region(s) of interest were cut using a Vibroslice (Campden Instruments, London, UK or Leica, Milton Keynes, UK) in ice-cold slicing solution ( $124 \mathrm{mM} \mathrm{NaCl}, 26 \mathrm{mM} \mathrm{NaHCO}_{3}, 3 \mathrm{mM} \mathrm{KCl}, 10 \mathrm{mM}$ glucose, $0.5 \mathrm{mM} \mathrm{CaCl}_{2}$, and $4 \mathrm{mM} \mathrm{MgCl}_{2}$ ) with 300-305 mOsm and oxygenated with $95 \% \mathrm{O}_{2}$ and $5 \% \mathrm{CO}_{2}$. Slices were then incubated at $30^{\circ} \mathrm{C}-34^{\circ} \mathrm{C}$ in a modified carbogenated recording solution $(124 \mathrm{mM} \mathrm{NaCl}, 26 \mathrm{mM}$ $\mathrm{NaHCO}_{3}, 3 \mathrm{mM} \mathrm{KCl}, 10 \mathrm{mM}$ glucose, $2.3 \mathrm{mM} \mathrm{CaCl}_{2}$, and $1.3 \mathrm{mM}$ $\mathrm{MgCl}_{2}$ ) with $300-305 \mathrm{mOsm}$ for 30 minutes. The tissue was then incubated in a HEPES-buffered Hanks' balanced salt solution containing protease $1 \mathrm{mg} / \mathrm{ml}$ Type XIV (Sigma-Aldrich) and maintained at $37^{\circ} \mathrm{C}$ with saturated $95 \% \mathrm{O}_{2}$ and $5 \% \mathrm{CO}_{2}$. Following the incubation period, the brain regions were rinsed three times with trituration solution $[140 \mathrm{mM}$ isethionic acid sodium salt, $2 \mathrm{mM} \mathrm{KCl}, 4.0 \mathrm{mM}$ $\mathrm{MgCl}_{2}, 0.1 \mathrm{mM} \mathrm{CaCl}, 23 \mathrm{mM}$ glucose, $15 \mathrm{mM} \operatorname{HEPES}(\mathrm{pH} 7.4$ ), $300 \mathrm{mOsm}$, and cells were dissociated by trituration using firepolished Pasteur pipettes. Hippocampal or cortical pyramidal neurons were identified by their triangle shape. Purkinje cells were identified by their large, round soma.

Tissue Slice Preparations. The brain or spinal cord was quickly removed and placed in an oxygenated, ice-cold beaker of slicing solution which contained $110 \mathrm{mM} \mathrm{NaCl}, 10 \mathrm{mM} \mathrm{MgCl}_{2}, 2 \mathrm{mM} \mathrm{KCl}$, $26 \mathrm{mM} \mathrm{NaHCO}_{3}, 1.25 \mathrm{mM} \mathrm{NaH}_{2} \mathrm{PO}_{4}, 0.5 \mathrm{mM} \mathrm{CaCl}_{2}, 10 \mathrm{mM}$ HEPES, and $15 \mathrm{mM}$ glucose (pH adjusted to 7.45 with $\mathrm{NaOH}$, osmolarity was 308-312 mOsm, oxygenated with $95 \% \mathrm{O}_{2}$ and $5 \% \mathrm{CO}_{2}$ ). After cooling in slicing solution for 2 to 3 minutes, the whole brain or lumbar region of the spinal cord was blocked (portions of anterior and posterior tissue removed) using a razor blade and then glued to the microslicer tray using cyanoacrylate (spinal cord was embedded in low gelling temperature agar). The tray containing the blocked and mounted tissue was filled with oxygenated, ice-cold slicing solution, and serial, coronal sections were cut at a thickness of $300 \mu \mathrm{m}$. Once all slices were cut, they were placed in a larger recovery chamber containing oxygenated 
slicing solution at room temperature $\left(18^{\circ} \mathrm{C}-20^{\circ} \mathrm{C}\right)$. The recovery chamber was in a large water bath which was initially at room temperature. Another slice keeper was placed into the water bath that contained artificial cerebrospinal fluid (aCSF) composed of $115 \mathrm{mM}$ $\mathrm{NaCl}, 1.5 \mathrm{mM} \mathrm{MgCl}_{2}, 4 \mathrm{mM} \mathrm{KCl}, 26 \mathrm{mM} \mathrm{NaHCO}_{3}, 1.25 \mathrm{mM} \mathrm{NaH}_{2} \mathrm{PO}_{4}$, $10 \mathrm{mM}$ HEPES, $1 \mathrm{mM} \mathrm{CaCl}_{2}$, and $15 \mathrm{mM}$ glucose at $\mathrm{pH} 7.45$, oxygenated with carbogen gas and osmolarity of 305-310 mOsm. The water bath was then turned on and the temperature was monitored inside the slice keeper. The recovery chamber temperature was allowed to reach $35^{\circ} \mathrm{C} \pm 0.4^{\circ} \mathrm{C}$ for a period of approximately 30 minutes, after which the brain or spinal cord slices were transferred to the slice keeper containing the aCSF (which was at approximately the same temperature). Approximately 15 minutes after the slice transfer, the water bath was turned off and the slice keeper containing aCSF was allowed to slowly return to room temperature $\left(18^{\circ} \mathrm{C}-20^{\circ} \mathrm{C}\right)$. Slices were used for recording after returning to approximately $32^{\circ} \mathrm{C}$. The optimal total recovery time for the brain slices was approximately 2-2.5 hours.

Patch-Clamp Recording. Electrophysiological recordings were made using borosilicate glass electrodes with 2- to 5 - $\mathrm{M} \Omega$ resistances. For recordings from transfected cells or acutely isolated neurons, all cells were voltage clamped at $-80 \mathrm{mV}$, and data were collected and digitized using Axoclamp 200B and Clampex software and hardware (Molecular Devices Inc., Sunnyvale, CA). For whole-cell recordings, the transfected HEK293T cells were bathed in an external solution (120.0 mM NaCl, $5.0 \mathrm{mM} \mathrm{BaCl}_{2}, 1.0 \mathrm{mM} \mathrm{MgCl}_{2}, 20.0 \mathrm{mM} \mathrm{CsCl}$, $10.0 \mathrm{mM}$ glucose, and $10.0 \mathrm{mM}$ HEPES, $\mathrm{pH}=7.4 \pm 0.3)$ containing $0.1 \mathrm{mM}$ 3-(2-carboxypiperazin-4-yl)propyl-1-phosphonic acid and $0.3 \mathrm{mM}$ tetrodotoxin (TTX) to block NMDA and voltage-dependent sodium channels, respectively. One of two electrode solutions was used: $160 \mathrm{mM} \mathrm{N}$-methyl-D glucamine, $4 \mathrm{mM} \mathrm{MgCl}_{2}, 40 \mathrm{mM}$ Na-HEPES (pH 7.4), $12 \mathrm{mM}$ phosphocreatine, and $2.0 \mathrm{mM} \mathrm{Na}_{2}-\mathrm{ATP}$ (pH 7.2 \pm 0.02 adjusted by $\mathrm{H}_{2} \mathrm{SO}_{4}$; or $135 \mathrm{mM} \mathrm{CsMeSO}_{4}, 8 \mathrm{mM} \mathrm{NaCl}, 10 \mathrm{mM}$ HEPES, $0.3 \mathrm{mM}$ EGTA, $4 \mathrm{mM} \mathrm{Mg-ATP}$, and $0.3 \mathrm{mM} \mathrm{Na-GTP}$. For some neuronal recordings, $1 \mathrm{mM}$ QX314 was added to the internal solution to block voltage-dependent sodium channels. The transfected HEK293T cell or the acutely isolated neuron was lifted and perfused with ligandcontaining external solution from a 16-barrel glass capillary pipette array positioned 100-200 $\mu \mathrm{m}$ from the cells. Each gravity-driven perfusion barrel was connected to a syringe positioned approximately $30 \mathrm{~cm}$ above the recording chamber. The solutions were switched by sliding the pipette array with an exchange rate of less than $20 \mathrm{~ms}$. Agonists and LY3130481 were applied where indicated.

The potency and efficacy of LY3130481 were calculated by measuring the amplitude ( $\mathrm{I}_{\mathrm{Glu}}$ Steady-state $)$ in the presence of LY3130481 normalized by $\mathrm{I}_{\mathrm{Glu}}$ Steady-state in the absence of LY3130481 to yield a relative $\mathrm{I}_{\mathrm{Glu}}$ Steady-state value and plotted as a function of compound concentration $\left(\log _{10}\right.$ [LY3130481]). The average and S.E.M. of $\log _{10} \mathrm{IC}_{50}$ and efficacy $\left(\mathrm{I}_{\max }\right)$ were calculated using the pooled relative

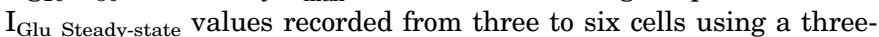
parameter sigmoidal curve-fitting function (Prism 7; GraphPad Software Inc., San Diego, CA). For each cell, five to six concentrations of LY3130481 were applied. For curve-fitting purposes, a zero-drug value, i.e., relative $I_{\text {Glu Steady-state }}$ without $L Y 3130481=1$, at [LY3130481] $=1 \times 10^{-13} \mathrm{M}$, was included 3 log units below the lowest LY3130481 concentration tested. No constraints were applied to either the bottom or top values for curve fitting, so the calculated $\mathrm{IC}_{50}$ is relative $\mathrm{IC}_{50}$ and represents the concentration at the midpoint between the top and bottom plateau. The Hill coefficient $(\mathrm{nH})$ was set to -1 because of the noncooperative property of LY3130481.

For recordings from brain slices, tissue was placed in a superfusion chamber mounted on a Nikon Eclipse FN-1 microscope. Neurons within the region of interest were visualized using infrared / differential interference contrast microscopy equipped with water immersion optics. The external solution contained $115 \mathrm{mM} \mathrm{NaCl}$, $1.5 \mathrm{mM} \mathrm{MgCl} 2,5 \mathrm{mM} \mathrm{KCl}, 26 \mathrm{mM} \mathrm{NaHCO}, 1.25 \mathrm{mM} \mathrm{NaH}_{2} \mathrm{PO}_{4}$, $10 \mathrm{mM}$ HEPES, $2 \mathrm{mM} \mathrm{CaCl}_{2}$, and $15 \mathrm{mM}$ glucose at $\mathrm{pH} 7.45$, oxygenated with $95 \% \mathrm{O}_{2}$ and $5 \% \mathrm{CO}_{2}$ and osmolarity of 300-305 mOsm.
The tissue slice in the chamber was continually superfused at a rate of $3 \mathrm{ml} / \mathrm{min}$ with oxygenated recording solution $\left(18^{\circ} \mathrm{C}-20^{\circ} \mathrm{C}\right)$. Compoundcontaining solutions were applied to the slice via whole chamber superfusion. Glass recording electrodes were filled with $130 \mathrm{mM}$ K-gluconate, $5 \mathrm{mM} \mathrm{NaCl}, 2 \mathrm{mM} \mathrm{MgCl} 2,10 \mathrm{mM}$ HEPES, $2 \mathrm{mM} \mathrm{MgATP}$, and $0.2 \mathrm{mM} \mathrm{NaGTP}$ at $\mathrm{pH} 7.2$, with osmolarity adjusted to $300 \mathrm{mOsm}$, and had a resistance of $3-6 \mathrm{M} \Omega$.

The whole-cell variant of the patch-clamp technique was used to record from visualized neurons, and initial access resistance $(\mathrm{Ra})$ was evaluated in voltage-clamp mode before switching to current-clamp mode. Bipolar stimulating electrodes were placed near the recording electrode to evoke AMPA receptor-dependent excitatory postsynaptic potentials (EPSPs) from ACC neurons or on the attached dorsal root to elicit responses from spinal neurons in the superficial laminae of the dorsal horn. Constant-current single-stimulation pulses $(100 \mu \mathrm{s}$, $50-500 \mu \mathrm{A}$ ) were delivered with a 20 -second interstimulus interval. EPSPs were amplified with a Multiclamp 700B amplifier (Molecular Devices Inc.), digitized, and acquired using Clampex software (version 10; Molecular Devices Inc.). Once the EPSP was stable in recording solution only, slices were superfused with recording solution containing $10 \mu \mathrm{M}$ bicuculline (bicuculline methochloride, Tocris 0130, molecular weight $(\mathrm{mw})=440.37$, batch $33 \mathrm{~A} / 124812), 50 \mu \mathrm{M}$ racemic (2R)-amino-5-phosphonovaleric acid (DL-APV) (DL-APV, Tocris 0105, $\mathrm{mw}=197.13$, batch $28 \mathrm{~A} / 98113$ ), and $1 \mu \mathrm{M}$ strychnine (spinal cord slice only, S8753; Sigma, mw $=370.87$ ) to block the GABA, NMDA, and glycine (in spinal cord slice) components of the EPSP, respectively, leaving only the AMPA-mediated EPSP. Once the AMPA-mediated EPSP was stable, a single concentration $(300 \mathrm{nM}$, or $3 \mu \mathrm{M})$ of the $\gamma 8$ TARP-dependent AMPA receptor antagonist ( $\gamma 8$-TDAA), LY3130481 $(\mathrm{mw}=382.44$, reference L37-H71437-028) dissolved in recording solution containing bicuculline, strychnine, and APV was superfused over the slice for 60 minutes. At the end of the 3130481 exposure period, the non-TARP-dependent AMPA antagonist GYKI53784 (303070, $\mathrm{mw}=352.39$, reference MN3-E07803-030) was applied at $50 \mu \mathrm{M}$ to show that the EPSP was completely AMPA mediated. Due to the extended time of the exposure to 3130481 during the experiment, a separate series of experiments were performed to determine the effect of time on the magnitude of the electrically evoked EPSP in which all solutions were the same except 3130481 was absent. The bicuculline/APV/strychnine solution and all compound-containing solutions contained $0.1 \%-0.2 \%$ dimethylsulfoxide.

The data from these experiments were analyzed in two different ways. First, the peak amplitude of the EPSPs was measured for the entire experimental duration. The EPSP amplitude was plotted against time, and an exponential smoothing algorithm was used to smooth the trending line of the plot. The smoothed data were then converted to a percentage of the experimental baseline time period average, and then individual experiment time points were averaged and S.E.M.s determined. In the second analysis method, the EPSP traces were analyzed for peak amplitude values by averaging at least five traces at the end of each treatment period and then converting that average value to a percentage of the experimental baseline time point. All parameters were analyzed using Clampfit version 10 (Molecular Devices), and data were compiled and summarized (means and S.E.M.s calculated) using Excel (Microsoft). Plotting of the data and statistical analysis of the processed data were performed using GraphPad Prism 7.

\section{In Vivo Electrophysiology}

Male SD rats (200-240 g; Harlan) were used. Electrophysiological recordings were performed in rats anesthetized with $1.5 \mathrm{~g} / \mathrm{kg}$ of urethane. Catheters were inserted into the jugular vein and carotid artery to administer drugs and monitor blood pressure, respectively. Mean arterial blood pressure was monitored continuously and was maintained at $>80 \mathrm{~mm} \mathrm{Hg}$, and body temperature was maintained at $37^{\circ} \mathrm{C}$ using a thermoprobe. Rats were mounted in a stereotaxic apparatus, and the lumbar enlargement was exposed via laminectomy 
(T12-L3). Following removal of the dura, the exposed spinal cord was kept moist with a small amount of artificial cerebrospinal fluid. A tungsten microelectrode ( $1 \mathrm{M} \Omega$; FHC, Bowdoinham, ME) was inserted into the spinal cord at level L4-L5 and advanced using a microdrive system (Burleigh, Fisher, NY) in 10- $\mu$ m increments. Once a single unit was isolated from background activity, the action potentials were monitored continuously by an analog signal delay unit and displayed on a storage oscilloscope after initial amplification through a low-noise alternating current (AC) differential amplifier. The electrophysiological activity was processed through a window discriminator and counted using the Spike2/CED 1401 data acquisition program (Cambridge Electronic Design Ltd., Cambridge, England). Single spinal dorsal horn sensory neurons were identified by brushing and mild pinching of the hind paw, and the receptive fields located on the plantar surface of the hind paw were then mapped using von Frey filaments. Only wide dynamic range (WDR) neurons were recorded in the present study. After a WDR neuron was identified, a pair of fine needles was inserted into the receptive field to deliver electrical stimulation. The threshold for action potential generation was determined by delivering single electrical pulses (2-ms duration) of increasing intensity. Wind up of WDR spike discharge was evoked by delivering a train of stimulation pulses (16 pulses in 32 seconds, $0.5 \mathrm{~Hz}, 2-\mathrm{ms}$ duration). Control responses were determined as the average of two consistent responses 10 minutes apart to stimulation of the receptive field. Wind-up discharge was calculated using methods similar to those described previously (Bee and Dickenson, 2009). The input value was defined as the number of action potentials evoked by the first of 16 stimulation pulses. The wind-up response was calculated by measuring the total cumulative number of action potential discharges evoked by the 16 stimulation pulses minus the input value. The effects of intravenous administration of vehicle, LY3130481 (1, 3, $10 \mathrm{mg} / \mathrm{kg}$ cumulative dosing), or GYKI52466 (6 mg/kg) on the wind-up discharge of WDR spinal sensory neurons were evaluated. Electrical stimulation pulses were delivered every 10 minutes to yield data points for 10 and 20 minutes post drug. At the conclusion of the experiments, rats were euthanized with urethane followed by cervical dislocation.

\section{Autoradiography}

Cohorts of $\gamma 8^{-1-}$ mice were obtained from Roger Nicoll (University of California, San Francisco) and bred at a contract breeder (Taconic). A detailed description of the generation of the $\gamma 8^{-1-}$ mouse line was published by Rouach et al. (2005). For these experiments, male $\gamma 8^{+/+}$ and $\gamma 8^{-1-}$ mice weighing $25-30 \mathrm{~g}$ were sacrificed by rapid decapitation and their brains quickly removed and frozen on dry ice. On the day of sectioning, frozen tissue was mounted on cryostat chucks and equilibrated to a cryostat temperature of $-20^{\circ} \mathrm{C}$ (object temperature approximately $-16^{\circ} \mathrm{C}$ ). Frozen sections of $12 \mu \mathrm{m}$ were cut and thaw-mounted on gelatin-coated slides. Sections were allowed to dry at room temperature and then stored at $-80^{\circ} \mathrm{C}$ in sealed containers. Slide-mounted tissue sections were thawed to room temperature before removal from the sealed containers, labeled with a scriber pen, preincubated at room temperature in assay buffer for 15 minutes to remove endogenous receptor ligands, and then dried completely under a stream of cool air. Sections were incubated on ice for 2 hours in $20 \mathrm{mM}$ HEPES, $400 \mathrm{mM} \mathrm{NaCl}$, and $10 \mathrm{mM} \mathrm{MgCl}$ containing $3 \mathrm{nM}\left[{ }^{3} \mathrm{H}\right]-\mathrm{LY} 3074158$, which corresponds to $\left[{ }^{3} \mathrm{H}\right]$-compound 3 in our previous report (Lee et al., 2017), with and without $10 \mu \mathrm{M}$ LY3187358 for nonspecific binding. Following incubation, the sections were rinsed twice by immersing in ice-cold assay buffer for 5 minutes, followed by a final quick rinse in ice-cold purified water, then dried under a stream of warm air. Slides were placed in film cassettes with Fuji BAS-TR2025 phosphoimaging plates and exposed for an empirically determined duration. Radioactive standards calibrated with known amounts of $\left[{ }^{3} \mathrm{H}\right]$ (ARC-0123; American Radiolabeled Chemicals, Inc.) were coexposed with each plate. Autoradiogram analysis was performed using a computer-assisted image analyzer (MCID7.0; Imaging Research Inc., St. Catharines, ON, Canada). Images were colorized using the MCID software and stored as TIFF files.

\section{Membrane Microtransplantation into Xenopus Oocytes}

Frozen samples of human spinal cord, cortex, and cerebellum were obtained from Tissue Solutions (Clydebank, Scotland) and Analytical Biologic Services Inc. (Wilmington, DE). Samples were from control donors. Brain samples were kept frozen at $-80^{\circ} \mathrm{C}$, and transport of the samples took place on dry ice. Membrane preparations from these tissues were prepared according to the method developed and described by Miledi et al. (2002, 2006), Eusebi et al. (2009), and Kato et al. (2016). In short, 0.1-0.5 g of tissue was homogenized in ice-cold glycine buffer (200 mM glycine, $150 \mathrm{mM} \mathrm{NaCl}, 50 \mathrm{mM}$ EGTA, $50 \mathrm{mM}$ EDTA, $300 \mathrm{mM}$ sucrose) to which $10 \mu \mathrm{l}$ of protease inhibitor cocktail (Sigma-Aldrich) was added per milliliter of glycine buffer. The homogenate was centrifuged at $4^{\circ} \mathrm{C}$ for 15 minutes at $9500 \mathrm{~g}$. The supernatant was subsequently centrifuged at $4^{\circ} \mathrm{C}$ for 2 hours at $100,000 \mathrm{~g}$ with an ultracentrifuge, and the pellet was resuspended in ice-cold assay buffer ( $5 \mathrm{mM}$ glycine). The protein concentration of the membrane preparations was measured using the Pierce BCA protein assay kit (Thermo Scientific, Rockford, IL) and was $\sim 3 \mathrm{mg} / \mathrm{ml}$. Aliquots of the suspensions were kept at $-80^{\circ} \mathrm{C}$ and were thawed just before injection into Xenopus oocytes.

Xenopus oocytes (stage V-VI) were removed from schedule I sacrificed frogs and defolliculated after treatment with collagenase type I ( $5 \mathrm{mg} / \mathrm{ml}$ calcium-free Barth's solution) for 4 hours at room temperature. Sixty nanoliters of membrane suspension was injected per oocyte using a variable volume microinjector (Drummond, Broomall, PA). After injection, oocytes were incubated at $18^{\circ} \mathrm{C}$ in a modified Barth's solution containing $88 \mathrm{mM} \mathrm{NaCl}, 1 \mathrm{mM} \mathrm{KCl}, 2.4 \mathrm{mM} \mathrm{NaHCO}_{3}$, $0.3 \mathrm{mM} \mathrm{Ca}\left(\mathrm{NO}_{3}\right)_{2}, 0.41 \mathrm{mM} \mathrm{CaCl}_{2}, 0.82 \mathrm{mM} \mathrm{MgSO}_{4}, 15 \mathrm{mM}$ HEPES, and $50 \mathrm{mg} / \mathrm{l}$ neomycin (pH 7.6 with $\mathrm{NaOH}$; osmolarity $235 \mathrm{mOsm}$ ). Experiments were performed on oocytes after 2-5 days of incubation.

Oocytes were placed in a recording chamber (internal diameter $3 \mathrm{~mm}$ ), which was continuously perfused with a saline solution (115 mM NaCl, $2.5 \mathrm{mM} \mathrm{KCl,} 1.8 \mathrm{mM} \mathrm{CaCl}_{2}, 1 \mathrm{mM} \mathrm{MgCl}_{2}$, and $10 \mathrm{mM}$ HEPES, pH 7.3 with $\mathrm{NaOH}, 235 \mathrm{mOsm}$ ) at a rate of approximately $10 \mathrm{ml} / \mathrm{min}$. Dilutions of drugs in external saline were prepared immediately before the experiments and applied by switching between control and drug-containing saline using a BPS-8 solution exchange system (ALA Scientific Inc., Westbury, NY). Oocytes were impaled by two microelectrodes filled with $3 \mathrm{M} \mathrm{KCl}(0.5-2.5 \mathrm{M} \Omega$ ) and voltage clamped using a Geneclamp 500B amplifier (Axon Instruments, Union City, CA). The external saline was clamped at ground potential by means of a virtual ground circuit using an $\mathrm{Ag} / \mathrm{AgCl}$ reference electrode and a platinum/irridium $(\mathrm{Pt} / \mathrm{Ir})$ current-passing electrode. The membrane potential was held at $-60 \mathrm{mV}$. The current needed to keep the oocyte's membrane at the holding potential was measured. Membrane currents were low-pass filtered (four-pole lowpass Bessel filter, $-3 \mathrm{~dB}$ at $10 \mathrm{~Hz})$, digitized $(50 \mathrm{~Hz})$, and stored on disc for offline computer analysis. Data are expressed as the mean \pm S.E.M. Experiments were performed at room temperature.

For the inhibition curve, currents were evoked by switching from control solution to a solution containing $100 \mu \mathrm{M}$ AMPA and $30 \mu \mathrm{M}$ cyclothiazide (CTZ). After 5 minutes of AMPA/CTZ perfusion, the solution was switched to AMPA/CTZ plus various concentrations of LY3130481 for 5 minutes. The amount of inhibition was calculated from the current amplitude at the end of LY3130481 application and the current amplitude of the AMPA/CTZ response just before LY3130481 application.

The concentration-inhibition curve was fitted according to the Hill equation. Curve fitting was performed using GraphPad Prism 3.01 software.

\section{Results}

Recombinant AMPA Receptors. Previous studies have found that LY3130481 potently and selectivity blocks AMPA receptors containing $\gamma 8$ subunits compared with AMPA receptors associated with other TARPs or without auxiliary 
A GluA1i +

LY3130481 ( $\mu \mathrm{M})$
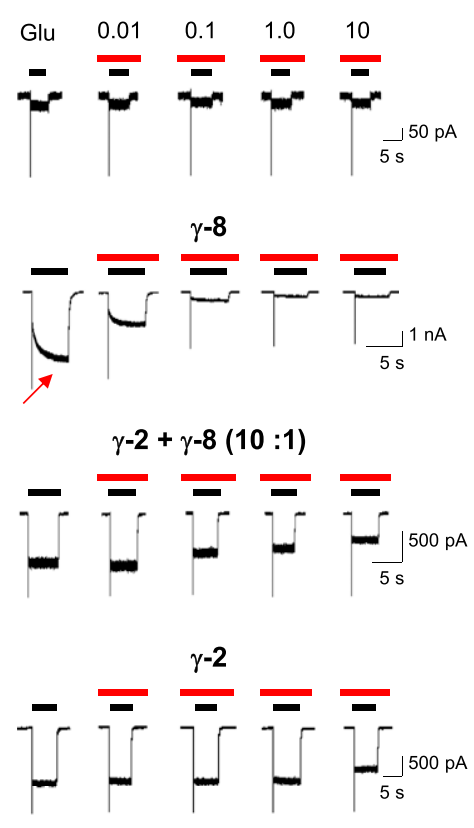

$\gamma-3+\gamma-8(10: 1)$

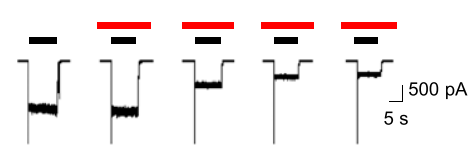

$\gamma-3$

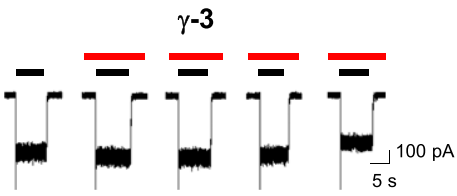

B

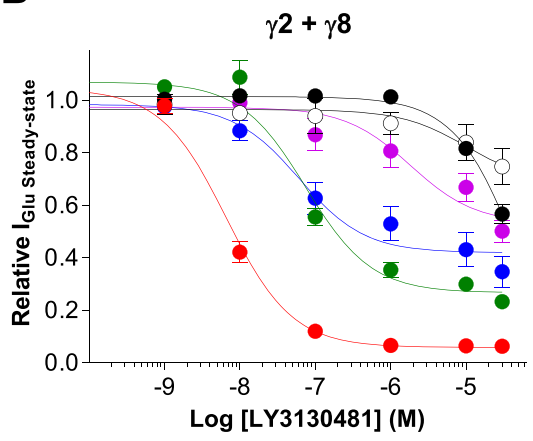

C

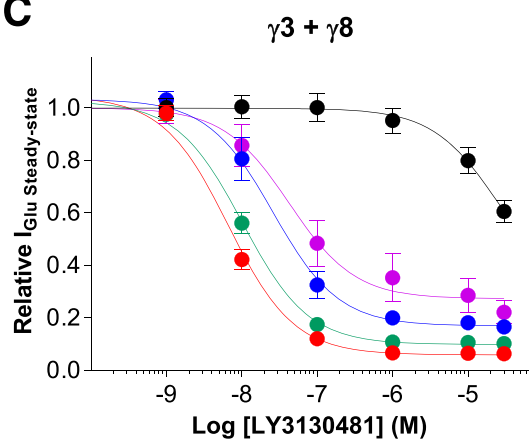

$-\mathrm{O}-$

- $\gamma 8$

- $\gamma 2$ or $\gamma 3$

$\gamma 2+\gamma 8$ or $\gamma 3+\gamma-8(1: 1)$

- $\gamma 2+\gamma 8$ or $\gamma 3+\gamma-8(3: 1)$

$-\gamma 2+\gamma 8$ or $\gamma 3+\gamma-8(10: 1)$
Fig. 1. The potency and efficacy of LY3130481 is determined by the amounts of $\gamma 2$ or $\gamma 3$ cotransfected with $\gamma 8$. (A) Representative current traces recorded from HEK293T cells recombinantly expressing GluA1i alone; in combination with $\gamma 2, \gamma 3$, or $\gamma 8$ alone; or with different amounts of $\gamma 8$ and $\gamma 2$ or $\gamma 3$. Note that the initial inward currents in Fig. 1 and subsequent figures do not reflect the peak of the glutamateevoked current due to the slower perfusion system used in these experiments. LY3130481 potently blocked currents from GluA1i $/ \gamma 8$ receptors but had minimal to no effect on GluA1i receptors alone or in combination with $\gamma 2$ or $\gamma 3$. Note the unique resensitization property of glutamate-evoked currents in GluA1 $/ \gamma 8$ receptors (arrow). Cotransfection of GluA1i with $\gamma 8$ and different ratios of $\gamma 2$ or $\gamma 3$ reduced the potency and efficacy of LY3130481 on Glu-evoked currents compared with GluA1/ $\gamma 8$ receptors alone. Note the elimination of resensitization in receptors coexpressed with $\gamma 8$ and $\gamma 2$ or $\gamma 3$ subunits. (B and C) Concentration-response profiles of LY3130481 on recombinant GluA1 receptors cotransfected with $\gamma 2, \gamma 3$, and $\gamma 8$ in different ratios. The relative amplitudes of glutamate-evoked steady-state currents are plotted as a function of LY3130481 concentration. Cotransfection of $\gamma 2$ with $\gamma 8$ in increasing ratios had a profound effect on the potency and efficacy of LY3130481. In contrast, cotransfection of $\gamma 3$ with $\gamma 8$ had more modest effects on the activity of LY3130481. The relative $\mathrm{I}_{\text {Glu Steady-state was calculated by }}$ dividing the current amplitude at the end of the glutamate application before and after exposure to LY3130481. Symbols reflect means \pm S.E.M., $n=3-6$ recordings/concentration. The $\mathrm{IC}_{50}$ and $\mathrm{I}_{\max }$ values for each transfectant are presented in Supplemental Table 1. proteins (Gardinier et al., 2016; Kato et al., 2016). This $\gamma 8$ specificity is not dependent on GluA subunit subtype (1-4), heteromeric configurations, or splice variation (Kato et al., 2016). Here, we extend these findings by examining the effects of varying the transfection ratios of $\gamma 8$ with other TARPs that are predominantly expressed in spinal $(\gamma 2)$ and cortical neurons $(\gamma 3)$ involved in pain signaling. The effects of LY3130481 were evaluated on HEK cells heterologously expressing GluA1i and $\gamma 8$ alone or in combination with different ratios of $\gamma 8$ and $\gamma 2$ or $\gamma 3$. Results showed that LY3130481 (0.001-30 $\mu \mathrm{M})$ had no appreciable effect on the glutamateevoked ( $1 \mathrm{mM}$ ) responses of GluA1i receptors expressed alone that were marked by a fast inward current that rapidly desensitized to a small steady-state level (Fig. 1A). Coexpression with any of the TARP subunits increased the amplitude of the glutamate-evoked desensitized current, and for $\gamma 8$-containing receptors, the current displayed a unique response characterized by a gradual increase in amplitude associated with prolonged glutamate application (Kato et al., 2010) (Fig. 1A; Supplemental Fig. 1). This response has previously been described as "resensitization" (Kato et al., 2010; Gill et al., 2011, 2012), although the mechanism is not known. Consistent with prior reports (Gardinier et al., 2016; Kato et al., 2016; Lee et al., 2017), LY3130481 potently and selectively blocked $\gamma 8$-containing GluA1i receptors with an $\mathrm{IC}_{50}$ of $6.6 \mathrm{nM}$, $(n=5)$ while having minimal to no effect on GluA1i receptors coexpressed with $\gamma 2$ or $\gamma 3$ subunits or CNIH-2 (Fig. 1; Supplemental Fig. 1; Supplemental Table 1) up to a concentration of $10 \mu \mathrm{M}$. The $\gamma 8$ selectivity of LY3130481 contrasted with the effects of the nonselective AMPA antagonist GYKI52466, which was equally potent and efficacious at blocking glutamateevoked currents from $\gamma 2$ - $(n=5)$ or $\gamma 8$-containing $(n=4)$ AMPA receptors (Fig. 2, A and B; Supplemental Table 2). In addition, cotransfection of $\gamma 2$ with $\gamma 8$ at a ratio of $1: 1$ or $10: 1(n=5)$ had no effect on the activity of GYKI52466 relative to that of either transfectant alone (Fig. 2, A and B; Supplemental Table 2).

Additional studies have previously demonstrated that LY3130481 has minimal to no effect as either an antagonist or positive allosteric modulator on related ionotropic glutamate receptors, including GluK2, GluN1/GluN2A, GluN1/GluN2B, or metabotropic glutamate receptors 1, 2, 3, 4, 5, and 8 (Kato et al., 2016). Moreover, LY3130481 does not have appreciable binding to 19 additional targets, including neurotransmitter receptors, ion channels, and transporters (Kato et al., 2016). Taken together, these data demonstrate that LY3130481 is highly selective for $\gamma 8$-containing AMPA receptors.

The effect of modifying TARP transfection ratios was next evaluated by cotransfecting GluA1i with different ratios of 
A
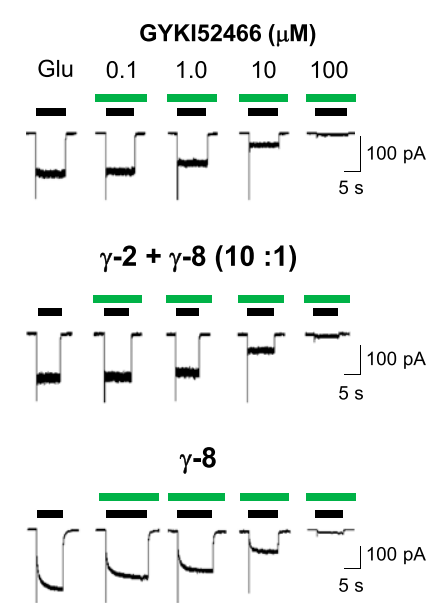

B
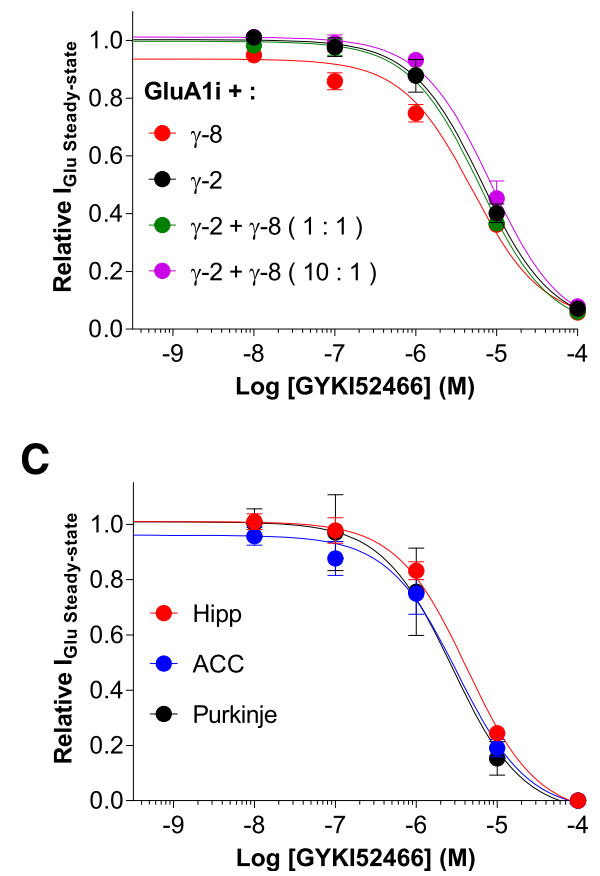

Fig. 2. The potency and efficacy of GYKI52466 is independent of TARP subunit expression. (A) Representative current traces recorded from HEK293T cells recombinantly expressing GluA1i in combination with $\gamma 2$ or $\gamma 8$ alone or after cotransfection of $\gamma 2$ and $\gamma 8$ in a ratio of 10:1. GYKI52466 blocked currents from GluA1i/ $\gamma 8(n=4)$ and GluA1i/ $\gamma 2(n=5)$ receptors with similar potency. Cotransfection of GluA1i with $\gamma 2$ and $\gamma 8$ in a ratio of 10:1 did not affect the potency of GYKI52466 on Glu-evoked currents compared with GluA1/ $\gamma 8$ receptors alone. Note the elimination of resensitization in receptors coexpressed with $\gamma 8$ and $\gamma 2$ subunits. (B) Concentrationresponse profiles of GYKI52466 on recombinant GluA1i receptors cotransfected with $\gamma 2$ and $\gamma 8$ in different ratios. The relative amplitudes of glutamate-evoked steady-state currents are plotted as a function of GYKI52466 concentration. Cotransfection of $\gamma 2$ with $\gamma 8$ in increasing ratios $2(n=5)$ had no effect on the potency and efficacy of GYKI52466. (C) Concentration-response profiles of GYKI52466 on acutely isolated hippocampal pyramidal neurons $(n=6)$, ACC pyramidal neurons $(n=5)$, and cerebellar Purkinje neurons $(n=4)$. GYKI52466 did not differentially affect glutamate-evoked currents from these cell types. The relative $\mathrm{I}_{\mathrm{Glu}}$ Steady-state was calculated by dividing the current amplitude at the end of the glutamate application before and after exposure to GYKI52466. Symbols reflect means \pm S.E.M. The $\mathrm{IC}_{50}$ and $\mathrm{I}_{\max }$ values for each transfectant are presented in Supplemental Table 2. Hipp, hippocampus.
cDNAs encoding $\gamma 8$ and $\gamma 2$ or $\gamma 3$. Varying the $\gamma 2: \gamma 8$ ratio from $0: 1$ to $10: 1$ produced a marked decrease in the potency and maximal efficacy (as measured at $10 \mu \mathrm{M}$ ) of LY3130481 in blocking glutamate-evoked currents (Fig. 1, A and B; Supplemental Table 1). The potency decreased by $\sim 270$-fold from an $\mathrm{IC}_{50}$ of $6.6 \mathrm{nM}$ ( $\gamma 8$ alone) to $1800 \mathrm{nM}(n=6)(10: 1)$, and the maximal efficacy was reduced from $>90 \%$ to $\sim 50 \%$ (Fig. 1B; Supplemental Table 1). Cotransfection of $\gamma 2$ and $\gamma 8$ cDNAs at different ratios with GluA1i produced an attenuation of the resensitization of inward current in response to prolonged glutamate application. Indeed, even a $\gamma 2: \gamma 8$ ratio of 1:3 effectively suppressed resensitization despite having modest effects on the potency and efficacy of LY3130481 (Fig. 1, A and B; Supplemental Fig. 1A). When potency and efficacy were plotted as a function of the percentage of resensitization, results showed that most of the $\gamma 2 / \gamma 8$ cotransfectants displayed no resensitization but were potently and efficaciously blocked by LY3130481 (Supplemental Fig. 1A). These data suggest that $\gamma 2$ and $\gamma 8$ TARPs can coassemble into functional AMPA receptors which display a range of sensitivity to LY3130481 that is dependent on the relative transfection stoichiometries of the two subunits.

Although altering the ratio of $\gamma 3: \gamma 8$ also decreased the potency and maximal efficacy of LY3130481 on GluA1i currents, the magnitude of these shifts was significantly smaller than for $\gamma 2$ cotransfectants. For example, a $\gamma 3: \gamma 8$ ratio of $10: 1$ shifted the potency of LY3130481 by approximately 7-fold $\left(\mathrm{IC}_{50}=42 \mathrm{nM}, n=6\right)$ compared with $\gamma 8$ alone, and the efficacy was reduced to $72.8 \%(n=6)$ (Fig. 1, A and C; Supplemental Table 1). Similar to $\gamma 2$ cotransfectants, $\gamma 3$ suppressed the resensitization response of $\gamma 8$-containing GluA1i receptors in a steeply ratio-dependent manner, indicating that $\gamma 3$ subunits can coassemble with $\gamma 8$ into functional receptors having a range of responses to LY3130481 (Fig. 1A; Supplemental Fig. 1B). The attenuation of $\gamma 8$-dependent resensitization by cotransfection with $\gamma 2$ or $\gamma 3$ is reminiscent of that with
CNIH-2 (Supplemental Fig. 1C) (Kato et al., 2010). Thus, while shifts in potency and maximal efficacy of LY3130481 on GluA1i currents were dependent on the ratio of cotransfection of these other auxiliary subunits with $\gamma 8$, the magnitude of the shifts were greatest when $\gamma 2$ was combined with $\gamma 8$.

The effect of TARP transfection ratios on the potency and efficacy of LY3130481 was also evident on putative heteromeric receptor complexes. For example, LY3130481 was highly potent and efficacious in suppressing glutamate-evoked currents from cells cotransfected with $\gamma 8$ in combination with GluA1i and GluA2i (Supplemental Fig. 2, A and B; Supplemental Table 3). In GluA1i/GluA2i-containing cells, y8 expression produced a resensitization of the glutamate-evoked response. Similar to GluA1i receptors, cotransfection of $\gamma 2$ and $\gamma 8$ in increasing ratios in GluA1i/GluA2i-containing cells blocked resensitization and markedly shifted the potency and efficacy of LY3130481 (Supplemental Fig. 2, A and B; Supplemental Table 3). Additional studies showed that although the potency and efficacy of LY3130481 were reduced in cells cotransfected with $\gamma 8$, GluA2i and GluA3i compared with homomeric GluA1i or GluA1i/GluA2i-containing cells (Supplemental Fig. 2, C and D), similar shifts of LY3130481 activity were observed with cotransfection of $\gamma 2$ and $\gamma 8$ in increasing ratios in GluA2i/GluA3i-containing cells (Supplemental Fig. 2D; Supplemental Table 4).

Native AMPA Receptors. The alterations in potency and efficacy of LY3130481 produced by varying the transfection ratio of $\gamma 8$ with other auxiliary subunits suggests that the compound will differentially affect native AMPA receptors in CNS neurons, depending on their levels of $\gamma 8$ expression. Initial studies investigated the relative expression of mRNA for $\gamma 2, \gamma 3$, and $\gamma 8$ TARPs and the GluA1 subunit quantified by reverse-transcription $\mathrm{qPCR}$ in samples from the frontal cortex, hippocampus, cerebellum, and spinal cord of rats. Consistent with previous reports (Tomita et al., 2003), $\gamma 2, \gamma 3$, and $\gamma 8$ expression were highest in the cerebellum, frontal cortex, and 
A

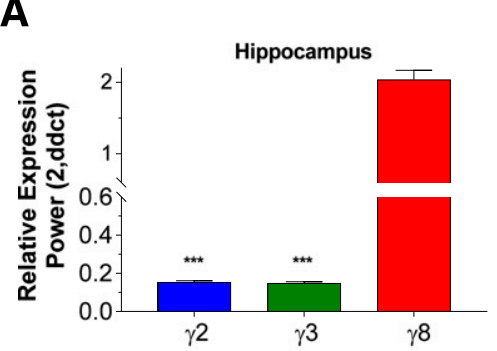

B

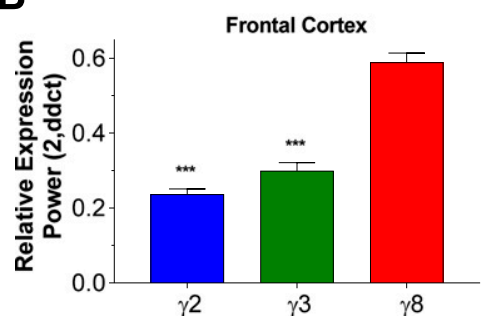

C

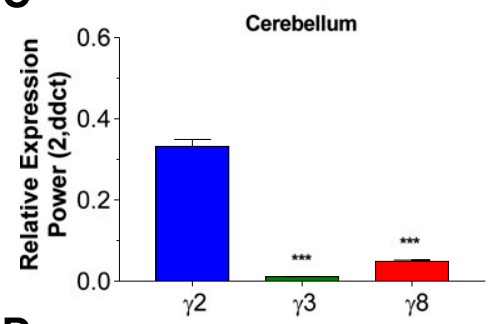

D

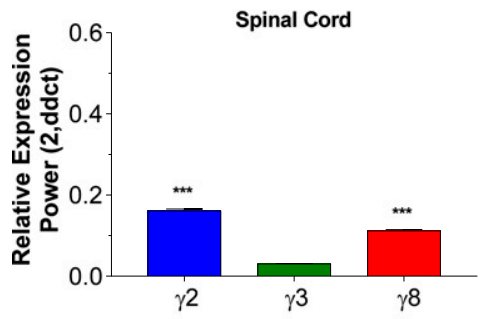

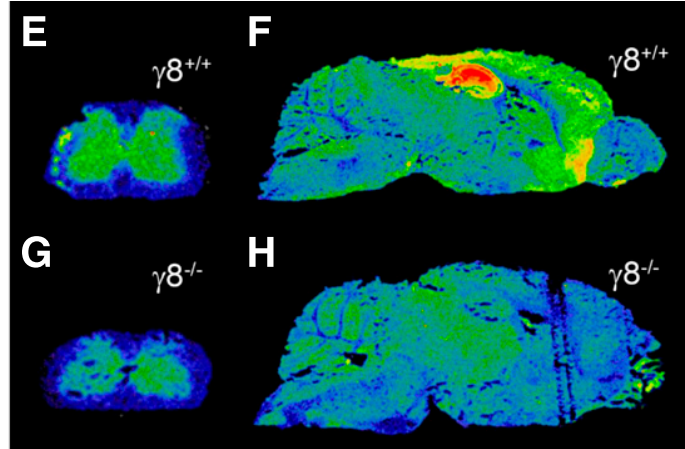

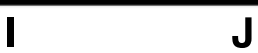

J

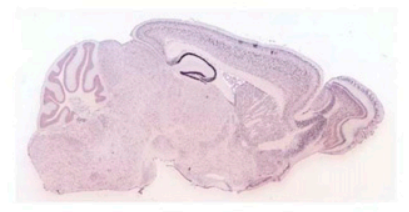

K

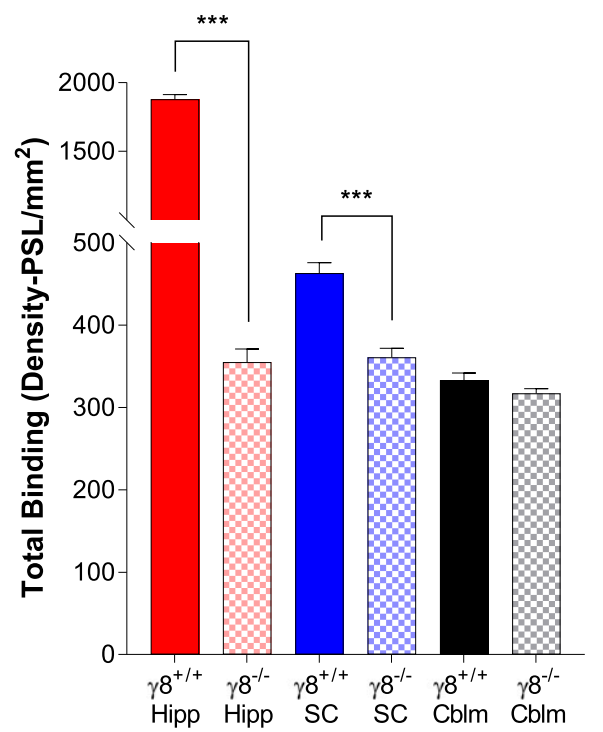

Fig. 3. Expression of TARP subunits in tissue from rat brain and spinal cord. (A-D) $\mathrm{qPCR}$ methods measured expression of $\gamma 2, \gamma 3$, and $\gamma 8$ in hippocampus, frontal cortex, cerebellum, and the lumbar region of the spinal cord. Consistent with previous reports, $\gamma 8$ expression was highest in the hippocampus followed by the frontal cortex, spinal cord, and cerebellum. Highest expression of $\gamma 2$ subunit was in the cerebellum and $\gamma 3$ was in the frontal cortex. The relative expression levels of $\gamma 2$ and $\gamma 3$ were significantly lower than $\gamma 8$ in the hippocampus and frontal cortex. The relative expression of $\gamma 2$ and $\gamma 8$ was similar in the spinal cord and significantly different from $\gamma 3$, and the expression level of $\gamma 2$ was higher than $\gamma 3$ or $\gamma 8$ in the cerebellum. Data presented in graphs are relative expression to Hprt1, expressed as $\Delta \Delta \mathrm{Ct}[\Delta \Delta \mathrm{Ct}=$ $\Delta$ Ctgene $-\Delta$ Ctnormalizer (Hprt1)]. Statistical analyses were conducted using one-way ANOVA followed by Dunnett's post hoc test $(* * * P<$ $0.0001, n=5$ for each group). Receptor density in spinal cord and brain slices from $\gamma 8^{+/+}(\mathrm{E}$ and $\mathrm{F})$ and $\gamma 8^{-/-}(\mathrm{G}$ and $\mathrm{H})$ mice using $\left[{ }^{3} \mathrm{H}\right]-$ LY3074158. (I and J) Expression pattern of the CACNG8 mRNA by in situ hybridization in a coronal section of mouse spinal cord and sagittal section of mouse brain from the Allen Mouse Brain Atlas (Lein et al., 2007). (K) Total binding densities measured in the hippocampus $(n=8)$, spinal cord $(n=12)$, and cerebellum $(n=8)$ from $\gamma 8^{+/+}$and $\gamma 8^{-/-}$mice. Statistical analyses were conducted using one-way ANOVA followed by Dunnett's post hoc test $(* * * P<$ 0.0001). Cblm, cerebellum; Hipp, hippocampus; PSL, photostimulated luminescence; SC, spinal cord. hippocampus, respectively (Fig. 3, A-D). Within the spinal cord, $\gamma 8$ and $\gamma 2$ mRNAs were expressed at relatively low levels but higher than $\gamma 3$ mRNA. In the frontal cortex, $\gamma 8$ mRNA abundance was greater than $\gamma 3$ and $\gamma 2$ expression. The mRNA GluA1 subunit had a rank order of expression from highest to lowest in the hippocampus, cerebellum, frontal cortex, and spinal cord by qPCR (data not shown).

The relative expression of $\gamma 2, \gamma 3$, and $\gamma 8 \mathrm{mRNA}$ in the hippocampus, frontal cortex, cerebellum, and spinal cord found in the present studies is consistent with the heterogeneous protein expression levels of these subunits in brain and spinal cord described previously (Larsson et al., 2013; Sullivan et al., 2017). With respect to the expression of these TARPs in the spinal cord, the modest levels of $\gamma 8 \mathrm{mRNA}$ were somewhat unexpected given the previous immunohistochemical studies (Larsson et al., 2013); however, see Sullivan et al. (2017). To clarify the distribution of $\gamma 8$ binding sites in brain and spinal cord, we leveraged a radiolabeled version $\left[{ }^{3} \mathrm{H}\right]-\mathrm{LY} 3074158$ [compound 3 in Lee et al. (2017)], a close congener of LY3130481. In functional assays examining glutamate-stimulated calcium flux, LY3074158 was inactive at GluA1i receptors alone or coexpressed with $\gamma 2$ but highly potent at blocking GluA1i receptors coexpressed with $\gamma 8\left[\mathrm{IC}_{50}=15.7 \pm 10.2 \mathrm{nM}\right.$ (mean \pm S.E.M.), $n=30]$. In addition, $\left[{ }^{3} \mathrm{H}\right]-\mathrm{LY} 3074158$ displayed high affinity $\left(\mathrm{K}_{\mathrm{D}}=4 \mathrm{nM}\right)$ for hippocampal AMPA receptors in binding assays. Together, these data confirm the potency and selectivity of LY3074158 for recombinant and native $\gamma 8$ associated AMPA receptors.

Autoradiograms were generated showing total binding of $\left[{ }^{3} \mathrm{H}\right]-\mathrm{LY} 3074158$ in tissue slices from brain and spinal cord of $\gamma 8^{+/+}$and $\gamma 8^{-/-}$mice. Consistent with the present $\mathrm{qPCR}$ results and previous in situ hybridization, immunohistochemical, and radioligand binding studies (Tomita et al., 2003; Lee et al., 2017; Sullivan et al., 2017), [ $\left.{ }^{3} \mathrm{H}\right]-\mathrm{LY} 3074158$ binding was highest in the hippocampus, moderate in the cortex, lower in the spinal cord, and at background levels in the cerebellum (Fig. 3, E-H and K). The $\gamma 8$-specific binding of $\left[{ }^{3} \mathrm{H}\right]-\mathrm{LY} 3074158$ was determined from autoradiograms from $\gamma 8^{-1-}$ mice and revealed a large reduction in the hippocampus and a smaller but significant reduction in the spinal cord, consistent with expected levels of $\gamma 8$ protein expression (Fig. 3K). For comparison, the relative $\gamma 8 \mathrm{mRNA}$ expression from in situ hybridization studies [Allen Brain Atlas (Lein et al., 2007)] is presented in Fig. 3, I and J. 
A

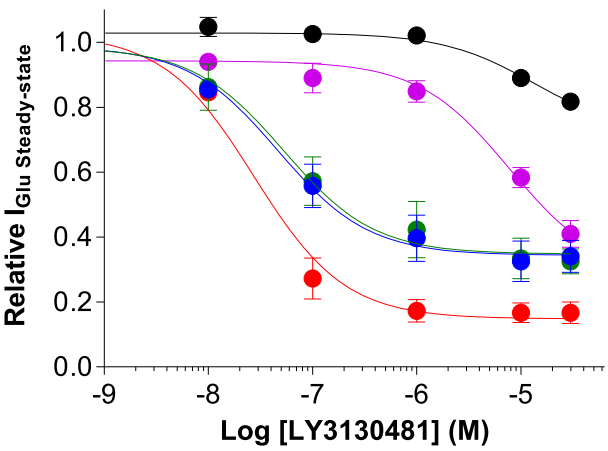

- Cerebellum: $I_{50}>10 \mu \mathrm{M}$
- Spinal cord: $\mathrm{IC}_{50}=7.7 \mu \mathrm{M}$
- SS: $\mathrm{IC}_{50}=52 \mathrm{nM}, I_{\max }: 65 \%$
- ACC: $\mathrm{IC}_{50}=46 \mathrm{nM}, I_{\max }: 65 \%$
- Hipp: $\mathrm{IC}_{50}=27 \mathrm{nM}, I_{\max }: 85 \%$
B

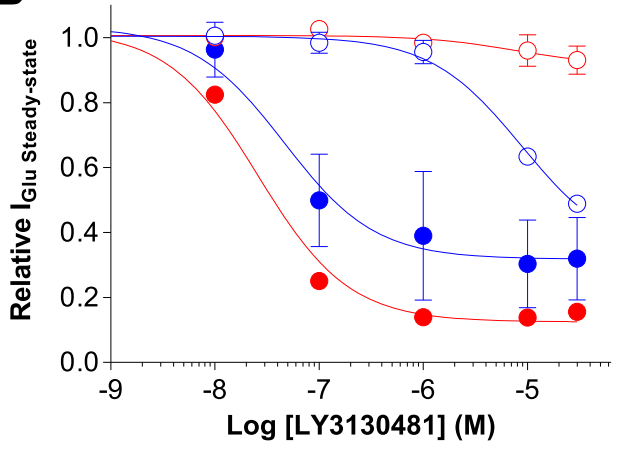

- $\gamma-8^{+/+}$Hipp: $I_{50}=26 \mathrm{nM}, I_{\max } 68 \%$

- $\gamma-8^{+/+}$ACC: $I_{50}=46 \mathrm{nM}, I_{\max } 68 \%$

- $\gamma-8^{-/-}$Hipp: $I_{50}=$ n.d.

- $\gamma-8^{-/-}$ACC: $I C_{50}=8.6 \mu \mathrm{M}$

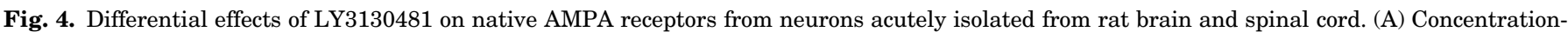

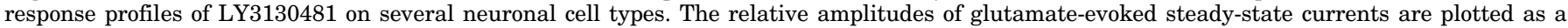

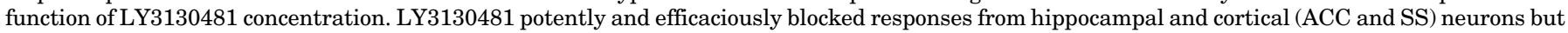

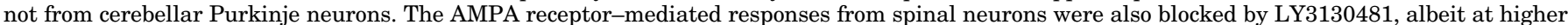

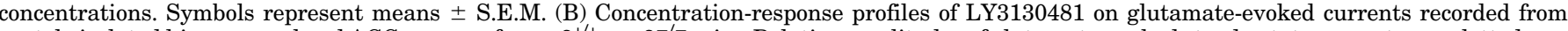

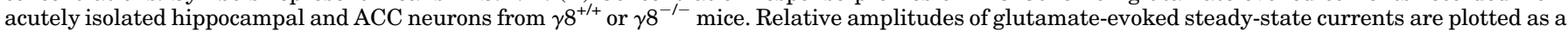

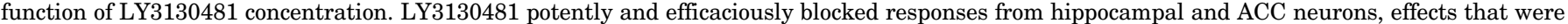
eliminated or markedly reduced in neurons from $\gamma 8^{-1-}$ mice. Symbols represent means \pm S.E.M. Hipp, hippocampus.

The functional consequences of the heterogeneous expression of TARPs were next investigated on neurons isolated from four distinct CNS regions. In agreement with previous studies (Kato et al., 2016), the potency and efficacy of LY3130481 were greatest on AMPA responses from acutely isolated hippocampal pyramidal neurons $\left(\mathrm{IC}_{50}=27 \mathrm{nM}, \mathrm{I}_{\max }=85 \%\right.$, $n=3$ ) (Fig. 4; Supplemental Table 3), which display the highest levels of $\gamma 8$ expression (Tomita et al., 2003) and $\left[{ }^{3} \mathrm{H}\right]-\mathrm{LY} 3074158$ binding in brain and were very similar to the potency and efficacy profiles of LY3130481 found for cells recombinantly coexpressing GluA1 with $\gamma 8$ (Fig. 1B; Supplemental Table 1). In contrast, LY3130481 had almost no effect on AMPA responses in isolated cerebellar Purkinje neurons $(n=3)$, which have high $\gamma 2$ but low $\gamma 8$ expression (Tomita et al., 2003) similar to cells recombinantly coexpressing GluA1i and $\gamma 2$ (Fig. 4A; Supplemental Tables 1 and 5). Consistent with the more modest expression of $\gamma 8$ and equivalent expression of $\gamma 2$ in spinal cord, the activity of LY3130481 on AMPA responses in these cells was considerably less potent $\left(\mathrm{IC}_{50}=7.7 \mu \mathrm{M}, n=6\right)($ Fig. 4 ; Supplemental Table 5) and similar to the responses of recombinant cells expressing higher ratios of $\gamma 2: \gamma 8$ (i.e., 10:1) (Fig. 1B; Supplemental Table 1). In comparison with spinal neurons, the effects of LY3130481 on isolated pyramidal neurons from ACC $\left(\mathrm{IC}_{50}=46 \mathrm{nM}, \mathrm{I}_{\max }=65.6 \%, n=3\right)$ and $\mathrm{SS}$ cortices $\left(\mathrm{IC}_{50}=\right.$ $52 \mathrm{nM}, \mathrm{I}_{\max }=65 \%, n=5$ ) were more potent and efficacious (Fig. 4A; Supplemental Table 5). In addition, the activity of LY3130481 on these neurons was in agreement with the relative expression of $\gamma 8$ and $\gamma 3$ in cortical regions and the more modest alterations in potency and efficacy conferred by recombinantly expressed $\gamma 8$ and $\gamma 3$ in stoichiometric studies (Fig. 1C; Supplemental Table 1). In contrast to the differential effects of LY3130481 on native receptors, GYKI52466 was equally potent and efficacious on hippocampal and ACC pyramidal neurons and cerebellar Purkinje cells (Fig. 2C; Supplemental Table 6).

The $\gamma 8$ dependence of LY3130481 activity on neuronal AMPA receptors was evaluated using isolated neurons from $\gamma 8^{+/+}$and $\gamma 8^{-/-}$mice. Initial studies showed that the potency and efficacy of LY3130481 on hippocampal $\left(\mathrm{IC}_{50}=\right.$ $\left.26 \mathrm{nM}, \mathrm{I}_{\max }=88 \%, n=3\right)$ and $\mathrm{ACC}\left(\mathrm{IC}_{50}=46 \mathrm{nM}, \mathrm{I}_{\max }=68 \%\right.$, $n=3$ ) neurons from $\gamma 8^{+/+}$mice were very similar to values found for these cell types harvested from rat brains (Fig. 4B; Supplemental Table 7). In contrast, the effect of LY3130481 on hippocampal neurons from $\gamma 8^{-/-}$mice was abolished up to concentrations of $30 \mu \mathrm{M}$, and the potency was reduced by nearly 200 -fold in ACC neurons $\left(\mathrm{IC}_{50}=8.5 \mu \mathrm{M}, n=4\right)$ (Fig. $4 \mathrm{~B}$; Supplemental Table 7). Interestingly, the concentrationresponse profile of LY3130481 on ACC neurons from $\gamma 8^{-1-}$ mice closely resembled the profile observed in cells recombinantly coexpressing GluA1i and $\gamma 3$ (see Fig. 1C) and is consistent with the presence of $\gamma 3$ in ACC. Taken together, these data demonstrate the $\gamma 8$ dependence of LY3130481 on the native neuronal AMPA receptors.

The relevance of LY3130481 activity in rodent tissue to that from humans was next assessed on AMPA receptors reconstituted from human cortex, spinal cord, and cerebellum into Xenopus oocytes in a manner similar to that previously reported for human hippocampus and cerebellum (Kato et al., 2016). LY3130481 suppressed AMPA receptor-mediated currents from heterologously expressed cortical AMPA receptors in a concentration-dependent manner with high potency $\left(\mathrm{IC}_{50}=\right.$ $53 \mathrm{nM}$ ) and efficacy $\left(\mathrm{I}_{\max } \sim 85 \%\right)$ similar to that for rodent cortical neurons (Figs. 4A and 5, A and B). Responses of reconstituted human spinal AMPA receptor were reduced by LY3130481, albeit with a lower potency $\left(\mathrm{IC}_{50}=485 \mathrm{nM}\right)$ and partial efficacy $\left(\mathrm{I}_{\max }=57 \%\right)$ similar to effects on AMPA receptors in acutely isolated rodent spinal neurons (Figs. 4A and 5, C and D). 
A

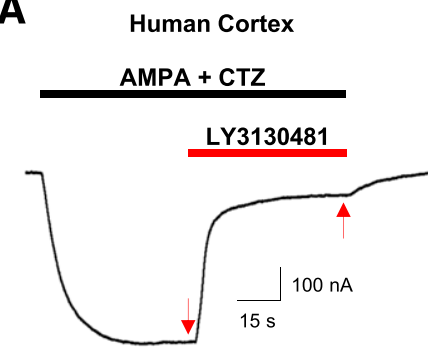

C

Human Spinal Cord

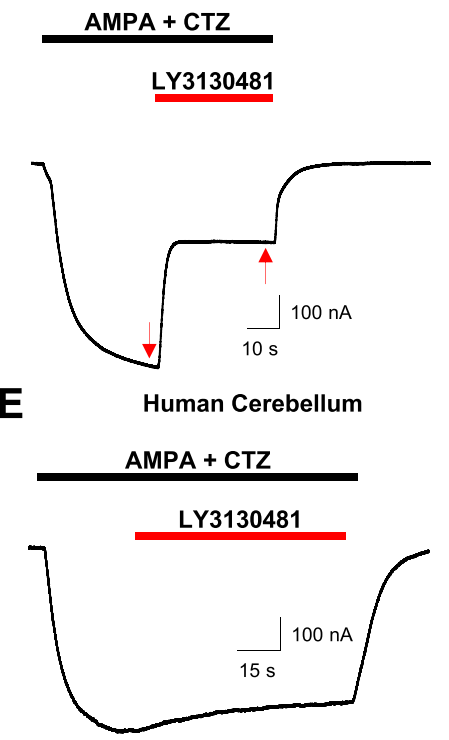

B

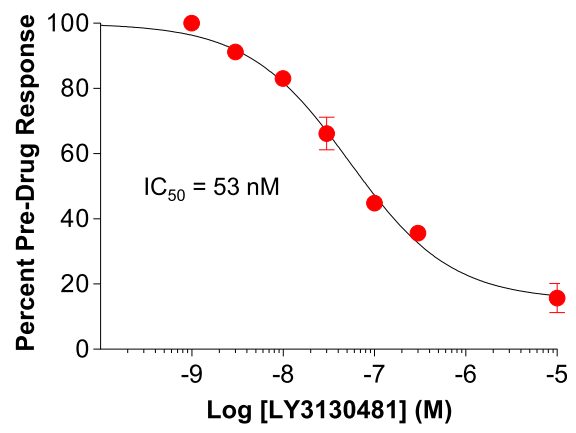

D

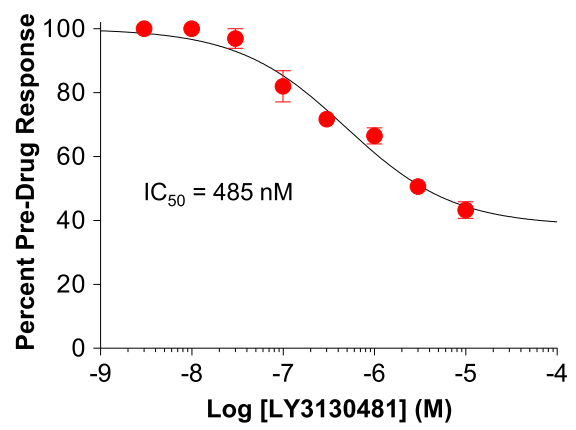

Fig. 5. Differential effects of LY3130481 on native AMPA receptors from human brain and spinal cord. (A, C, and E) Representative current traces evoked by application of AMPA + CTZ on Xenopus oocytes microimplanted with human, cortical, spinal cord, or cerebellar tissue. LY3130481 (10 $\mu \mathrm{M})$ was coapplied after application of AMPA $(100 \mu \mathrm{M})+\mathrm{CTZ}(30 \mu \mathrm{M})$. Note that LY3130481 produced a near-complete suppression of cortical AMPA receptor responses, a partial block of spinal cord AMPA receptor activity, and minimal effect on cerebellar AMPA receptor responses. (B and D) The amplitudes of AMPA + CTZ-evoked currents in the absence and presence of LY3130481 were measured at the time points indicated by the arrows in (A) and (C). The current amplitudes in the presence of LY3130481 were normalized to the predrug amplitude and plotted as a function of LY3130481 concentration for cortical (B) and spinal cord (D) AMPA receptors. Symbols reflect means \pm S.E.M., $n=2-5$ recordings/concentration.
By comparison, LY3130481 minimally suppressed AMPA receptor-mediated currents from reconstituted human cerebellar tissue (Fig. 5E). Collectively, these studies indicate that the differential effects of LY3130481 on distinct neuronal populations are predicted by the regional expression of $\gamma 8, \gamma 2$, and $\gamma 3$ in rodent and human brain.

Modulation of Synaptic Transmission. The partial blockade of AMPA responses of isolated spinal and cortical neurons suggested that the compound should display a similar reduction of AMPA receptor-mediated synaptic responses in these two CNS regions, albeit with different potencies. To test this hypothesis, the glutamatergic synaptic responses of ACC pyramidal neurons were evoked by stimulation of fibers in the proximal apical dendritic region of these neurons in a tissue slice preparation. Because of the dense recurrent excitatory collateral network among cortical neurons, the synaptic response is composed of both mono- and polysynaptic components, yielding a complex EPSP (Baumbarger et al., 2001). The AMPA receptor-mediated component of the synaptic response was isolated by blocking $\mathrm{GABA}_{\mathrm{A}}$ and $\mathrm{GABA}_{\mathrm{B}}$ receptors and NMDA receptors with bicuculline (1 $\mu \mathrm{M})$, SCH50911 (2 $\mu \mathrm{M})$, and APV $(50 \mu \mathrm{M})$, respectively. Previous studies examining the effects of LY3130481 on synaptic transmission in hippocampal slices have shown that the drug requires approximately 30 minutes to reach a steady-state level (Kato et al., 2016). To evaluate the potential confound of a decrement in ACC responses associated with long exposure times, initial studies measured the amplitude of the ACC
EPSP over time and demonstrated that the responses were stable for at least 70 minutes (Fig. 6A). Subsequent experiments demonstrated that 0.03 and $0.3 \mu \mathrm{M}$ LY3130481 reduced the AMPA receptor-dependent EPSP in ACC neurons to $35.8 \% \pm 5.2 \%$ and $41.8 \% \pm 2.7 \%(n=4)$ of control responses, respectively (Fig. 6, $\mathrm{A}$ and $\mathrm{B}$ ). In contrast, the nonselective AMPA receptor antagonist GYKI53784 (50 $\mu \mathrm{M})$ abolished the AMPA receptor-mediated responses of ACC neurons (Fig. 6B).

The effects of LY3130481 were also studied on the AMPA receptor-mediated synaptic transmission in spinal dorsal horn neurons evoked by stimulation of dorsal roots. Results showed that 0.03 and $0.3 \mu \mathrm{M}$ LY3130481 suppressed responses of spinal neurons in a concentration-dependent manner to $87.6 \% \pm 3.8 \%$ and $53.9 \% \pm 1.7 \%(n=4)$ of control responses (Fig. 6, C and D). Time control experiments demonstrated that the amplitude of the synaptic response of dorsal horn neurons was stable for at least 70 minutes, indicating that the effects of LY3130481 were not likely due to deterioration of the recording. Similar to its effects on synaptic responses of ACC neurons, GYKI53784 (50 $\mu \mathrm{M})$ completely blocked the EPSP in spinal neurons (Fig. 6D). Collectively, these data support the hypothesis that potency and efficacy of LY3130481 on AMPA receptor-mediated synaptic transmission in different CNS neurons depend on the relative abundance of the $\gamma 8$ subunit.

Pharmacokinetics and Receptor Occupancy. To inform in vivo studies, the pharmacokinetic properties and CNS 
A

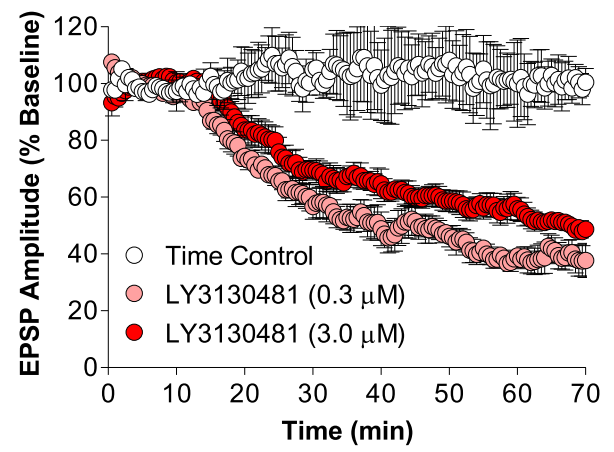

B

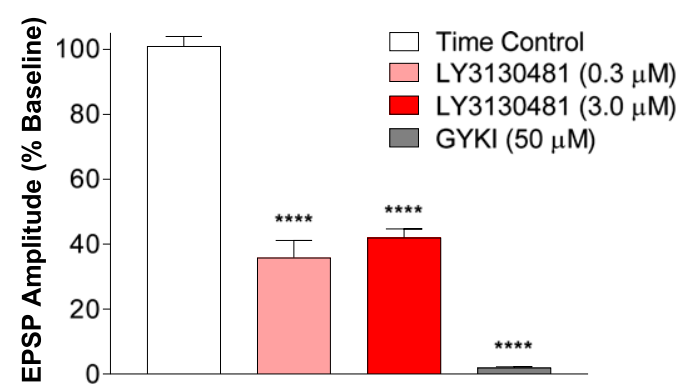

C

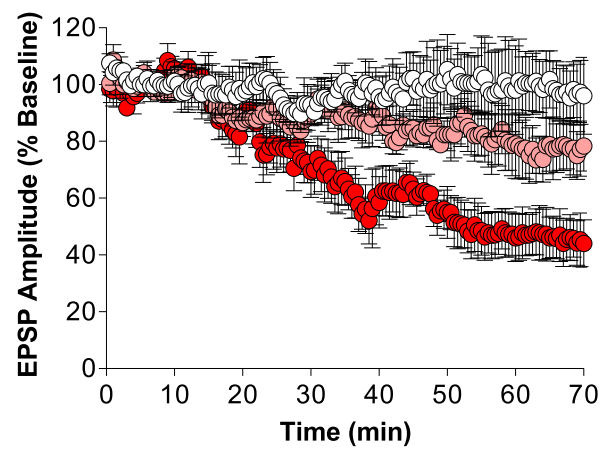

D

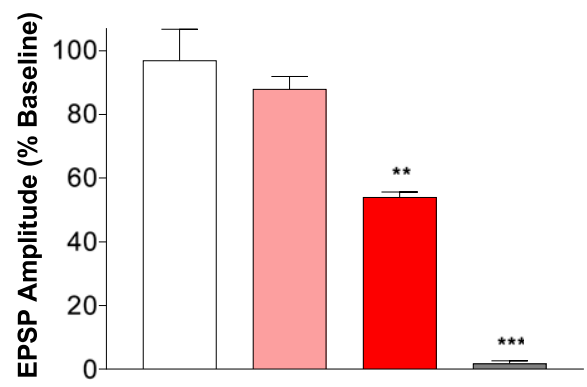

Fig. 6. LY3130481 suppresses AMPA receptor-dependent EPSPs in rat ACC pyramidal neurons and dorsal horn spinal cord neurons in vitro. (A) Plot of EPSP amplitudes in ACC neurons in control solution $(n=4)$ or in the presence of LY3130481 $(0.3,3.0 \mu \mathrm{M})(n=4)$ as a function of time from recording onset. (B) Plot of the normalized EPSP amplitude (mean \pm S.E.M.) in ACC neurons in control solution $(n=4)$ or solutions containing LY3130481 (0.3, 3.0 $\mu \mathrm{M})(n=4)$ or GYKI53784 (50 $\mu \mathrm{M})(n=4)$. (C) Plot of EPSP amplitudes in spinal neurons in control solution $(n=4)$ or in the presence of LY3130481 $(0.3$, $3.0 \mu \mathrm{M})(n=4)$ as a function of time from recording onset. (D) Plot of the normalized EPSP amplitude in spinal neurons in control solution $(n=4)$ or solutions containing LY3130481 $(0.3,3.0 \mu \mathrm{M})(n=4)$ or GYKI $(50 \mu \mathrm{M})(n=4)$. ***P $<0.001 ; * * * * P<0.0001$

receptor occupancy characteristics of LY3130481 were assessed. Plasma concentration-time profiles following PO $(3 \mathrm{mg} / \mathrm{kg})$ and i.v. (1 mg/kg) administration in rats showed LY3130481 had high oral bioavailability (97\%) (Fig. 7A). Oral dosing delivered compound to plasma with a $\mathrm{C}_{\max }$ of $628 \mathrm{ng} / \mathrm{ml}$ (1.6 $\mu \mathrm{M}), \mathrm{T}_{\max }$ of 1.3 hours, and half-life of 2.4 hours. The clearance of LY3130481 $(\mathrm{Cl}=11 \mathrm{ml} / \mathrm{min}-\mathrm{kg})$ was relatively low compared with hepatic blood flow ( $\mathrm{Qh}=55 \mathrm{ml} / \mathrm{min}-\mathrm{kg})$ and contributed to the high oral bioavailability. The occupancy of $\gamma 8$-containing AMPA receptors in brain was measured following oral administration of LY3130481 $(0.1-30 \mathrm{mg} / \mathrm{kg})$ using a pretreatment time of 1 hour. LY3130481 displayed a dose-dependent increase in plasma concentration that was correlated with CNS $\gamma 8$-AMPA receptor occupancy. Inspection of the dose-occupancy relationship showed that LY3130481 had an $\mathrm{ED}_{50}$ of $2.9 \mathrm{mg} / \mathrm{kg}(n=4$, pooled data) and a maximal efficacy of $96 \%$ occupancy at $30 \mathrm{mg} / \mathrm{kg}$ (Fig. 7B). These data were used to guide dosing for subsequent in vivo PD assessments.

Modulation of Synaptic Plasticity. A role for AMPA and NMDA receptors in the short-term enhanced responsiveness of spinal sensory neurons to repetitive c-fiber stimulation (i.e., wind up) and the induction of long-term increases in spinal neuron excitability (i.e., central sensitization) produced by stimulation or peripheral nerve injury is well established (Davies and Lodge, 1987; Dickenson and Sullivan, 1987; Dickenson, 1990; Svendsen et al., 1998; Herrero et al., 2000). Nonselective blockade of AMPA receptors prevents the induction of both forms of synaptic plasticity, as well as suppresses the expression of previously established sensory neuron hyperexcitability (Dickenson and Sullivan, 1987; Dickenson, 1990; Svendsen et al., 1998; Herrero et al., 2000). Given the
A

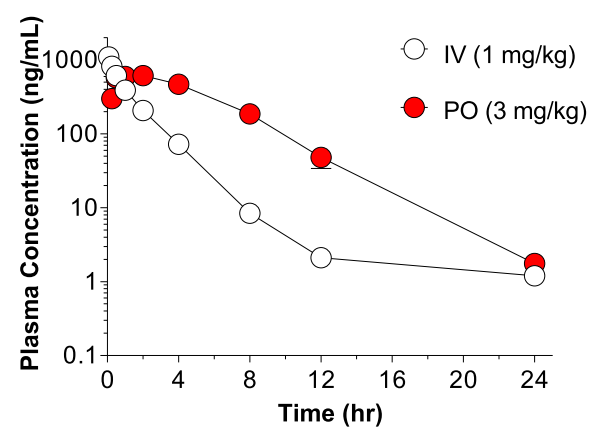

B

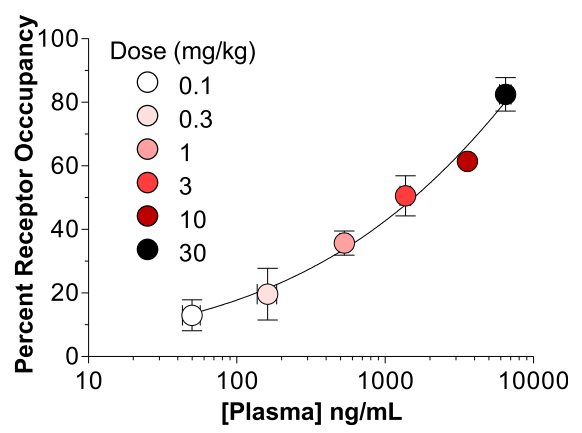

Fig. 7. Pharmacokinetics and receptor occupancy for LY3130481 in rat. (A) Plot of plasma concentration of LY3130481 as a function of time in Sprague-Dawley rats following intravenous $(1 \mathrm{mg} / \mathrm{kg})$ or oral $(3 \mathrm{mg} / \mathrm{kg})$ administration. (B) The percentage receptor occupancy of $\gamma 8$-containing AMPA receptors for each dose of LY3130481 (0.1-3.0 mg/kg, PO) is plotted as a function plasma concentrations. In these experiments, $30 \mathrm{mg} / \mathrm{kg}$ of LY3130481 was associated with occupancy levels approaching $100 \%$. Symbols represent means \pm S.E.M.s. 
A
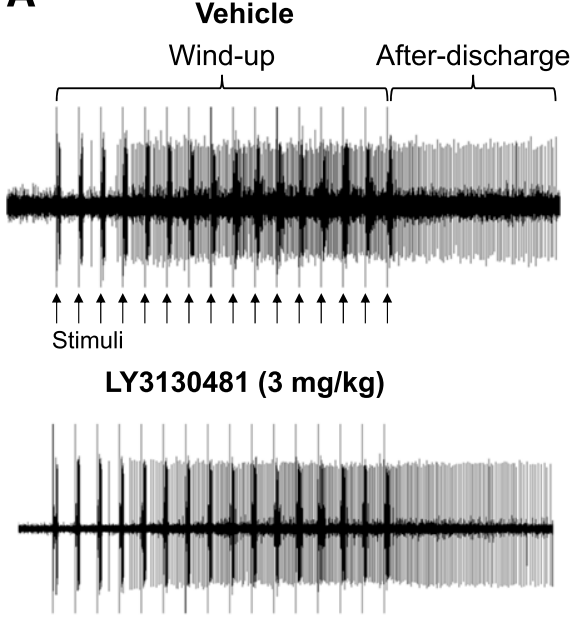

LY3130481 (10 mg/kg)

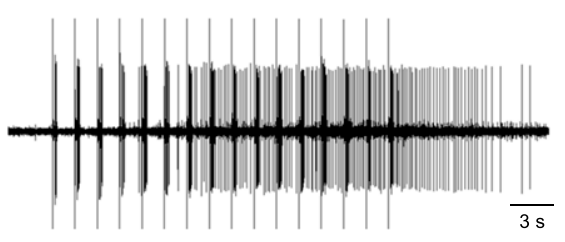

B

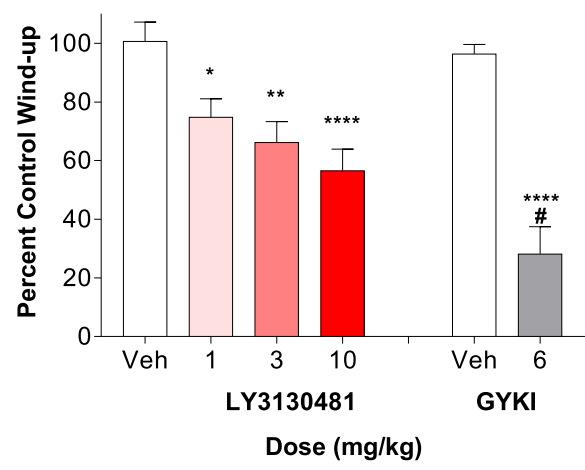

C

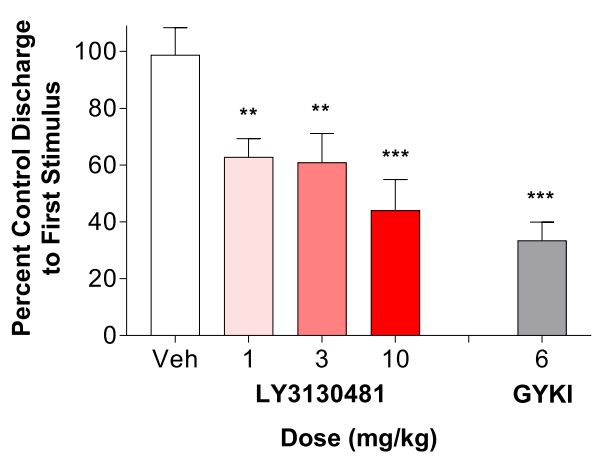

Fig. 8. LY3130481 attenuates wind-up discharge of spinal sensory neurons. (A) Extracellular single-unit recordings from WDR neurons in the dorsal horn of the lumbar spinal cord region in vivo in response to repetitive stimulation of the receptive field in the hindpaw. A train of 16 stimuli delivered at $1 \mathrm{~Hz}$ (arrows) elicited responses from sensory neurons characterized by an increase in discharge probability in response to later stimuli in the train compared with earlier stimuli (wind up). In addition, several seconds of ongoing discharge could be observed following the last stimulus in the train (after discharge). Intravenous administration of vehicle had minimal effect on wind up or after discharge. In contrast, LY3130481 (1-10 mg/kg) dose-dependently reduced the number of discharges over the course of the train of stimuli. After discharges also were suppressed. (B) Plot of the wind-up response of spinal neurons (normalized to baseline responses, mean \pm S.E.M.) following intravenous administration of vehicle $(n=8)$ and LY3130481 (1-10 $\mathrm{mg} / \mathrm{kg}, n=7$ to 8$)$ or GYKI $(6 \mathrm{mg} / \mathrm{kg}$, $n=4)$ ). (C) Plot of the number of discharges of spinal neurons in response to the first stimulus in the 16-stimulus train (mean \pm S.E.M.) following intravenous administration of vehicle $(n=8)$ and LY3130481 (1-10 mg/kg, $n=7$ to 8) or GYKI $(6 \mathrm{mg} / \mathrm{kg}, n=5)$. $* P<0.05 ; * * P<0.01$; $* * * P<0.001$. effects of LY3130481 on AMPA receptor-dependent synaptic responses of spinal neurons in vitro, the present studies tested the hypothesis that selective blockade of $\gamma 8$-containing AMPA receptors could also attenuate wind up of spinal sensory neurons to c-fiber stimulation in vivo. Consistent with previous studies (Davies and Lodge, 1987; Dickenson and Sullivan, 1987), repetitive stimulation of peripheral nerves evoked an increase in discharge of single WDR neurons to successive stimuli (i.e., wind up) (Fig. 8A). Intravenous delivery of the vehicle solution did not affect the wind-up discharge of WDR neurons (105.1\% $\pm 7.8 \%$ of pretreatment, $n=8)$. However, administration of cumulative doses $(1,3,10 \mathrm{mg} / \mathrm{kg}$, i.v.) of LY3130481 produced a dose-dependent decrease in wind-up discharge of c-fiber inputs to WDR neurons (Fig. 8, A and B). Wind-up responses were significantly, but only partially, reduced to $74.8 \% \pm 6.2 \%(n=8), 66.3 \% \pm 7.0 \%(n=8)$, and $56.6 \% \pm 7.3 \%(n=7)$ of control values following administration of 1-, 3-, and 10-mg/kg doses, respectively (Fig. 8B). In comparison, systemic administration of the nonselective AMPA receptor antagonist GYKI52466 (6 mg/kg) suppressed wind-up discharge to $28.2 \% \pm 9.2 \%(n=4)$ of control values (Fig. 8B), which is significantly greater than the highest dose of LY3130481 (10 mg/kg). The suppressive effects of LY3130481 also were evident in the discharge to the initial stimulus in the repetitive train in the wind-up studies. LY3130481 reduced discharge to the first stimulus in the repetitive train to $62.8 \% \pm 6.5 \%(n=8), 60.9 \% \pm 10.2 \%$ $(n=7)$, and $44.0 \%+10.9 \%(n=7)$, of control values following administration of $1-, 3-$, and $10-\mathrm{mg} / \mathrm{kg}$ doses, respectively. GYKI52466 (6 mg/kg) also reduced discharge to the initial stimulus to $33.4 \% \pm 6.5 \%(n=5)$ of control responses (Fig. $8 \mathrm{C}$ ).

Due to the cumulative dosing paradigm, plasma exposure of LY3130481 was not measured in these animals. Rather, in a separate experiment, animals were dosed intravenously with either 1 or $10 \mathrm{mg} / \mathrm{kg}$ of LY3130481, and sample analyses yielded LY3130481 plasma levels (concentrations) of $1140 \pm$ $177 \mathrm{ng} / \mathrm{ml}(n=3)(3 \mu \mathrm{M})$ and $11,485 \pm 857 \mathrm{ng} / \mathrm{ml}(n=7)$ $(30 \mu \mathrm{M})$, respectively. Examination of the exposure-occupancy curve for LY3130481 indicates that these plasma concentrations are predicted to be associated with CNS $\gamma 8$-AMPA receptor occupancy levels of $\sim 50 \%$ and $100 \%$, respectively (Fig. 8B). These data demonstrate that LY3130481 reduced glutamatergic synaptic transmission and short-term synaptic plasticity of c-fiber inputs to spinal sensory neurons in vivo. However, the suppression of excitatory responses was only partial despite near-complete occupancy of CNS $\gamma 8$-AMPA receptors, suggesting that only a subpopulation of synaptic AMPA receptors on WDR neurons contain the $\gamma 8$ subunit.

Attenuation of Nocifensive Behavior. Modulation of the nocifensive behaviors of conscious animals in response to noxious stimuli, tissue injury, or nerve damage has been used extensively to evaluate the therapeutic potential of novel agents. Intraplantar injection of formalin has been shown to initiate dramatic increases in spontaneous activity of c-fibers and discharge of WDR neurons in the spinal cord and ACC and SS cortical neurons (Chapman and Dickenson, 1995; McCall et al., 1996). Coupled with these excitatory responses, animals exhibit a unique behavioral response to formalin characterized by an initial bout of nocifensive responding that subsides approximately 5-10 minutes after formalin injection, followed by a longer period of responding lasting approximately 45-60 minutes. This behavioral response pattern is associated with an analogous pattern of discharge of WDR neurons, with both indices being dependent on enhanced glutamatergic synaptic input (Haley et al., 1990; Coderre and Melzack, 1992; Hunter and Singh, 1994). Previous studies have demonstrated that the formalin-induced nocifensive behavior can be reduced by systemic administration of broad-spectrum 
AMPA receptor antagonists, albeit with significant motor and sedative side effects (Simmons et al., 1998). The present studies tested the hypothesis that selective blockade of $\gamma 8$ containing AMPA receptors would suppress formalin-induced behaviors without confounding CNS side effects. Indeed, oral administration of LY3130481 attenuated formalin-induced nocifensive behaviors in both Sprague-Dawley rats (Fig. 9A) and CD-1 mice (Fig. 10A) in a dose-dependent manner. The $\mathrm{ED}_{50}$ values of LY3130481 in both species were comparable ( rat $=3.7 \mathrm{mg} / \mathrm{kg}$, mice $=4.7 \mathrm{mg} / \mathrm{kg}$ ), and the decrease in nocifensive behaviors was observed in the absence of any overt impairment as measured by rotorod performance (Fig. 10C). In contrast, although GYKI52466 also dose-dependently suppressed nocifensive behaviors in the mouse formalin assay, marked impairment on rotorod performance was observed in an overlapping dose range (Fig. 10, B and D). These data are consistent with previous reports on global AMPA antagonists (Simmons et al., 1998).

Further support for a role of $\gamma 8$-containing AMPA receptors in the antinocifensive effects of LY3130481 came from an examination of the dose-occupancy and dose-response relationships in rats for LY3130481 in CNS $\gamma 8$-AMPA receptor occupancy and formalin assays, respectively. The data revealed that the dose-dependent increase in CNS receptor occupancy was inversely related to nocifensive responding in the late phase of the formalin response (Fig. 9B). Indeed, the potency for occupancy of CNS $\gamma 8$-containing AMPA receptors $\left(\mathrm{ED}_{50}=2.9 \mathrm{mg} / \mathrm{kg}\right)$ was nearly identical to the potency for attenuation of formalin-induced behaviors $\left(\mathrm{ED}_{50}=3.7 \mathrm{mg} / \mathrm{kg}\right)$.

The $\gamma 8$ dependence of the antinocifensive actions of LY3130481 was subsequently explored using $\gamma 8^{+/+}$and $\gamma 8^{-/-}$mice. Initial studies showed that $\gamma 8^{-/-}$mice had similar levels of responding to formalin injection compared with $\gamma 8^{+/+}$mice (Fig. 11A). This may reflect compensation mechanisms in response to the loss of the gene throughout development, allowing alternative mechanisms to underlie the formalin-induced behavior. When LY3130481 was administered at the $\mathrm{ED}_{50}$ dose, nocifensive behavior was present in the $\gamma 8^{+/+}$but not $\gamma 8^{-/-}$mice, indicating that the suppression of nocifensive responding was mediated by interaction with $\gamma 8$-containing AMPA receptors (Fig. 11A). In contrast, neither the reduction in nocifensive behaviors nor the motor impairment produced by GYKI52466 was affected in $\gamma 8$-deficient mice, indicating that other subtypes of AMPA receptors can support antinociceptive effects and are also responsible for motor dysfunction (Fig. 11, B and C).

Similar to intraplantar formalin, proinflammatory agents such as monoiodoacetic acid or CFA administered into the intra-articular space are known to increase c-fiber discharge after injection into paw and joint (Djouhri et al., 2006; Schuelert et al., 2010). The behavioral responses to proinflammatory agents are characterized by shifts in weight bearing, leading to alterations in gait. We have recently established an assay in which intra-articularly administered CFA induces both spatial and temporal deficits in normal gait, revealed by forced ambulation on a treadmill, which can be partially restored by a number of clinically effective drugs (i.e., opioids, nonsteroidal anti-inflammatory drugs, antinerve growth factor (NGF) antibody) (Adams et al., 2016). A significant advantage of this assay is that it encompasses a collection of natural ambulatory endpoints (e.g., range of motion, stance/swing ratio, and paw print size) that permit a
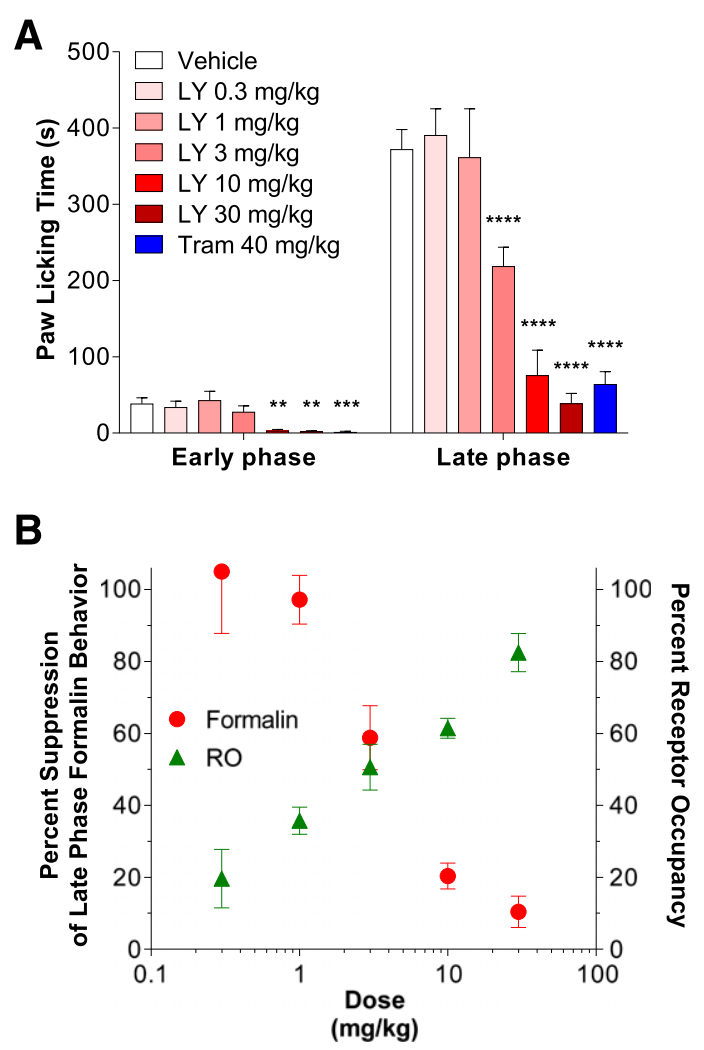

Fig. 9. LY3130481 reduces formalin-induced nocifensive behavior in rats. (A) Oral administration of LY3130481 $(0.3-30 \mathrm{mg} / \mathrm{kg}, 30$ minutes pretreatment) dose-dependently attenuated formalin-induced paw licking behavior in Sprague-Dawley rats. The positive control, tramadol (40 mg/kg), was also effective in decreasing paw licking. Effects of both drugs were observed in both the early (0-5 minutes) and late (10-60 minutes) phases of the formalin-induced behavioral profile. The $\mathrm{ED}_{50}$ for LY3130481 was $3.7 \mathrm{mg} / \mathrm{kg}$. Bars represent means \pm S.E.M.s, $n=$ 8-16 animals per group. $* * P<0.01$; $* * * P<0.001$; $* * * * P<0.0001$. (B) Plot of the dose dependence of the percentage suppression of nocifensive responding in the late phase of the formalin response [from (A)] versus the percentage CNS $\gamma 8 / \mathrm{AMPA}$ receptor occupancy (from Fig. 7B) for LY3130481. Results show that the dose-dependent increase in CNS 88/AMPA receptor occupancy is associated with an increase in the suppression of nocifensive behaviors after formalin treatment. Symbols represent means \pm S.E.M.s, $n=8-16$ animals per group. RO, receptor occupancy.

more refined examination of the effects of putative analgesics. The present studies tested the hypothesis that selective blockade of $\gamma 8$-containing AMPA receptors would attenuate CFA-induced gait deficits as a function of dampening glutamatergic signaling along pain pathways. Intra-articular injection of CFA rendered animals lame in the affected paw. Oral administration of LY3130481 dose-dependently restored CFA-induced gait deficits across all four indices within the composite gait score, including paw print size, stance/swing ratio, normalized stance distance, and range of motion (Fig. 12; Supplemental Fig. 3; Supplemental Video 1). The effects of LY3130481 on the composite gait score were comparable to those of tramadol $(40 \mathrm{mg} / \mathrm{kg})$. In contrast to responses in the formalin assay, higher doses were required to produce a statistically significant restoration in gait impairment.

SNL can induce a long-term sensitization of both spinal and supraspinal glutamatergic pathways that manifest as enhanced responses to normally innocuous tactile stimuli (Kim and Chung, 1992; Leem et al., 1996; Ossipov et al., 2000). Acute spinal administration of nonselective AMPA receptor 
A
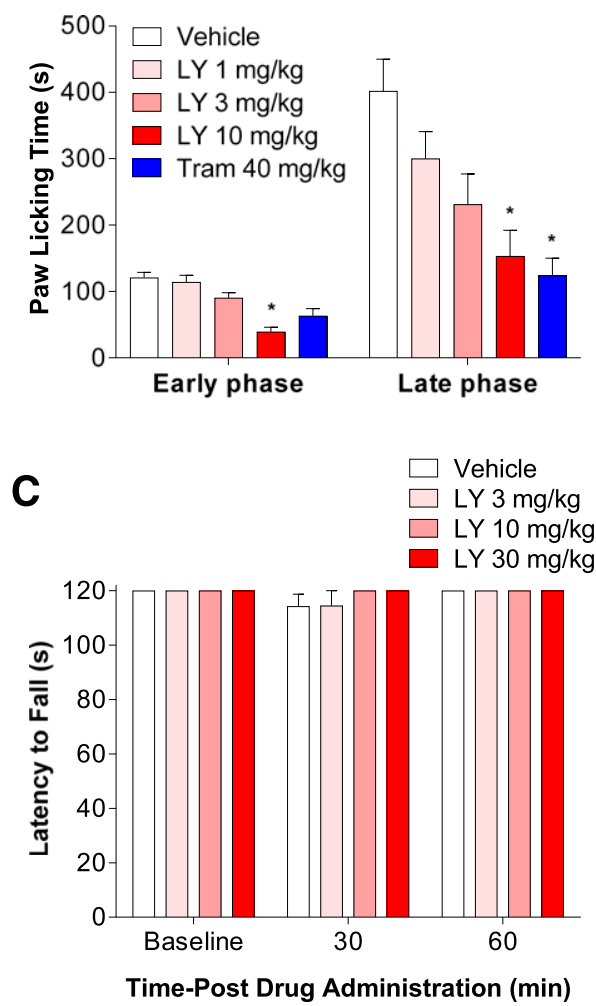

B
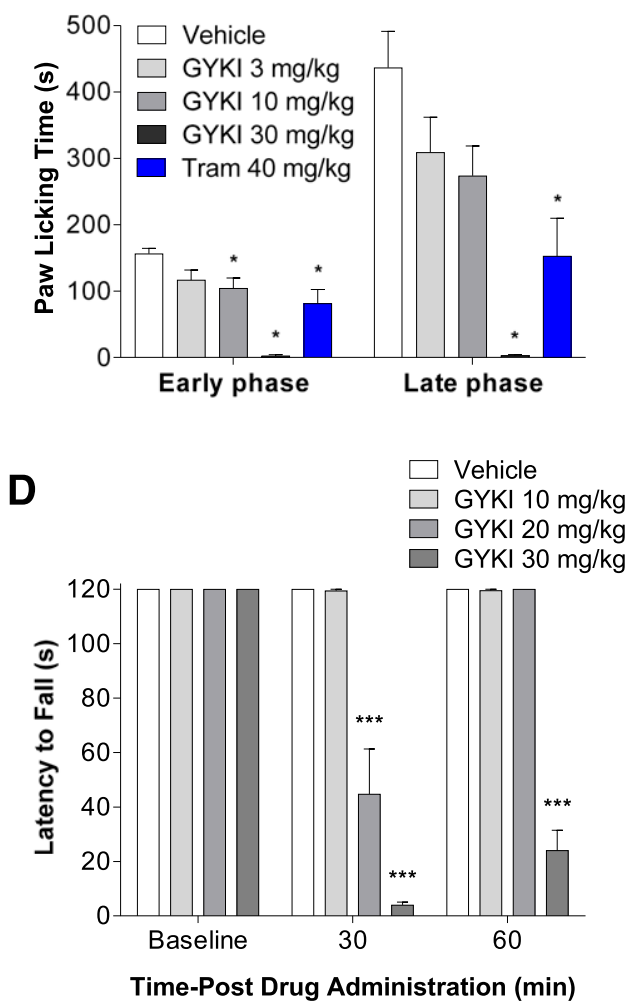

Fig. 10. LY3130481, but not GYKI52466, reduces formalin-induced behavior in mice without motor impairment. (A and B) Oral administration of LY3130481 (1-10 mg/kg, 30 minutes pretreatment) or GYKI52466 (3-30 mg/kg) dose-dependently attenuated formalin-induced paw licking behavior in CD-1 mice. The positive control, tramadol $(40 \mathrm{mg} / \mathrm{kg}$ ), was also effective in decreasing paw licking. Effects of all drugs were observed in both the early (0-5 minutes) and late (10-60 minutes) phases of the formalin-induced behavioral profile. The $\mathrm{ED}_{50}$ for LY3130481 was $4.7 \mathrm{mg} / \mathrm{kg}$, whereas the $\mathrm{ED}$ 50 for GYKI52466 was $13.4 \mathrm{mg} / \mathrm{kg}$. Bars represent means \pm S.E.M.s, $n=10$ animals per group. Statistical analyses were conducted using two-way ANOVA followed by Dunnett's post hoc test; ***P $<0.0001$. (C and D) Rotorod performance was measured following oral administration of LY3130481 and GYKI across the efficacious dose range for each compound. LY3130481 did not impair rotorod performance at either 30 or 60 minutes post dosing. Conversely, administration of GYKI52466 at 20 and $30 \mathrm{mg} / \mathrm{kg}$ produced significant impairment in motor performance as evidenced by an inability to remain on the rotorod for the entire 2-minute testing period at 30 and 60 minutes post dosing. Bars represent means \pm S.E.M.s, $n=10$ animals per group. Statistical analyses were conducted using two-way ANOVA followed by Dunnett's post hoc test; *** $P<0.0001$.

blockers has been shown to suppress the enhanced discharge of WDR spinal neurons, as well as the tactile allodynia after SNL (Leem et al., 1996). The present studies evaluated the efficacy of LY3130481 on tactile allodynia after SNL. Results showed that in contrast to gabapentin $(75 \mathrm{mg} / \mathrm{kg})$, oral administration of LY3130481 (30 mg/kg) did not affect tactile allodynia after a single dose (Fig. 12B). However, after 5 days of dosing, LY3130481 significantly attenuated tactile allodynia to levels equivalent to gabapentin (Fig. 12B). While further studies are needed to identify the mechanism(s) responsible for the differential efficacy of LY3130481 in the repeated dosing regimen, the discrepancy may be dependent on the prolonged $\gamma 8 / \mathrm{AMPA}$ receptor antagonism to attenuate the sensitization of glutamatergic pathways associated with chronic nerve injury and/or an accumulation of compound and $\gamma 8$ /AMPA receptor occupancy at key CNS sites of action. Regardless, these data demonstrate that selective blockade of 88-containing AMPA receptors can have beneficial effects on nocifensive behaviors in rats several weeks after nerve injury. In addition, although efficacy required multiple days of dosing, the data suggest a lack of tolerance to repeated administration of LY3130481, which is a common observation for other mechanisms of action (i.e., mu opiate receptor agonists) (Zhou et al., 2013).

\section{Discussion}

Properties of LY3130481. Modulation of AMPA receptors has been pursued as a therapeutic approach for numerous neurologic and psychiatric disorders (O’Neill et al., 2004). Given the widespread expression of AMPA receptors, a considerable challenge has been achieving a degree of regional selectivity in altering AMPA receptor function to minimize adverse side effects. We recently discovered LY3130481, which is a potent and selective blocker of AMPA receptors coassembled with TARP $\gamma 8$ subunits. The present studies demonstrated coexpression of $\gamma 2$ with $\gamma 8$ in increasing ratios reduced the potency and efficacy of LY3130481 to a much greater extent than coexpression with $\gamma 3$. Consistent with these findings, the activity of LY3130481 was highest on hippocampal neurons, modestly lower on ACC and SS neurons, and significantly lower on spinal and cerebellar neurons which displayed ratios of $\gamma 8$ to $\gamma 2$ and/or $\gamma 3$ expression of 13:1, $2: 1,0.7: 1$, and $0.15: 1$, respectively. The $\gamma 8$-dependence was confirmed by the absence of activity of LY3130481 on hippocampal neurons and marked reduction on ACC neurons from $\gamma 8$-deficient mice. The translatability of these findings was established by the similar potency and efficacy of LY3130481 on AMPA receptors from rodent and human cortex, spinal cord, and cerebellum. Collectively, these results indicate that 
A

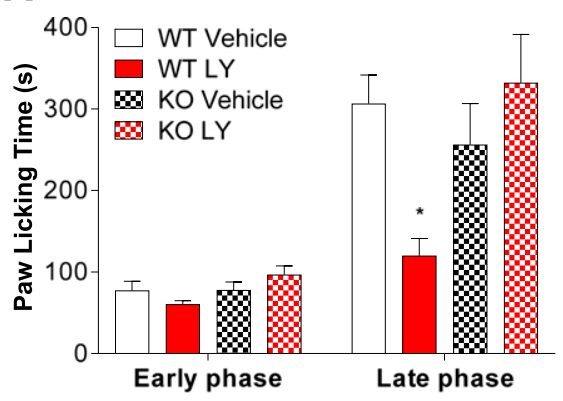

B

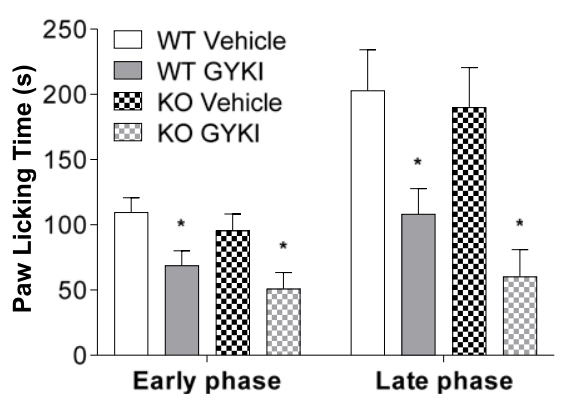

C

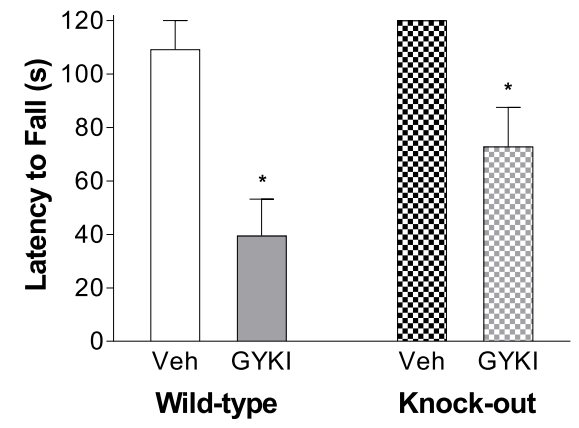

Fig. 11. Attenuation of mouse formalin-induced nocifensive behavior by LY3130481, but not GYKI52466, is $\gamma 8$-dependent. The calculated $\mathrm{ED}_{50}$ values for LY3130481 (4.7 mg/kg) and GYKI52466 (13.4 mg/kg) derived from doseresponse experiments in $\gamma 8^{+/+}$mice (see Fig. 10) were evaluated in $\gamma 8^{+/+}$or $\gamma 8^{-/-}$mice. (A) LY3130481 significantly decreased formalininduced nocifensive behavior in the late phase in $\gamma 8^{+/+}$mice but did not affect paw licking in the $\gamma 8^{-1-}$ mice. (B) Conversely, the suppressive effects of GYKI52466 on formalin-induced paw licking were evident in both $\gamma 8^{+/+}$and $\gamma 8^{-1-}$ mice. (C) The motor-impairing effects of GYKI52466 (13.4 mg/kg, PO) observed in $\gamma 8^{+/+}$ mice were retained in $\gamma 8^{-1-}$ mice. Bars represent means \pm S.E.M.s, $n=10$ animals per group; ${ }^{*} P<0.05$. KO, knockout; WT, wild type. the differential effects of LY3130481 are predicted by both the degree of $\gamma 8$ expression as well as the relative expression to other TARPs in distinct neuronal populations in both rodent and human brain.

LY3130481 Modulates Glutamatergic Synaptic Transmission. Central sensitization in spinal and supraspinal somatosensory pathways is postulated to underlie many symptoms common to chronic pain disorders (e.g., allodynia) (Latremoliere and Woolf, 2009) and depends on the initial depolarization produced by glutamate activation of AMPA receptors and sequential recruitment of NMDA receptors (Davies and Lodge, 1987; Yoshimura and Jessell, 1990; Woolf and Thompson, 1991; Farkas and Ono, 1995) in response to injury of peripheral afferents (Wall and Woolf, 1984; McNamara et al., 2007). A critical role for $\gamma 8$ TARPs in trafficking AMPA receptors to synapses, mediating excitatory transmission, and underlying long-term synaptic plasticity has been established in hippocampal circuits (Rouach et al., 2005; Fukaya et al., 2006). Immunohistochemical studies have shown regional expression of $\gamma 8$ in the dorsal horn of the spinal cord and SS and ACC cortices and subcellular coexpression with some, but not all, AMPA receptors at spinal and cortical synapses (Inamura et al., 2006; Larsson et al., 2013; Sullivan et al., 2017). These data suggested that LY3130481 should suppress, but not eliminate, excitatory synaptic transmission in dorsal horn and cortical neurons. As predicted, LY3130481 attenuated AMPA receptor-dependent EPSPs, whereas GYKI53784 eliminated excitatory responses in both neuronal subtypes. Consistent with the higher total and relative (to $\gamma 2$ and $\gamma 3$ ) expression of $\gamma 8$ in the cortex, LY3130481 was correspondingly more potent in reducing ACC versus spinal EPSPs.

The effects of LY3130481 also were studied on the wind up of spinal WDR neurons, which depends on the interplay between AMPA and NMDA receptors (Davies and Lodge, 1987; Yoshimura and Jessell, 1990; Stanfa and Dickenson, 1999). LY3130481 dose-dependently suppressed wind up with a maximal efficacy of approximately 55\%. LY3130481 also partially blocked responses to the initial stimulus in the train in vivo, consistent with effects on EPSPs in spinal neurons in vitro. Plasma exposures indicated that the $\gamma 8$-AMPA receptor occupancy achieved with the highest dose $(10 \mathrm{mg} / \mathrm{kg})$ approached $100 \%$, suggesting that the partial reduction in wind up was not due to incomplete $\gamma 8$-AMPA receptor occupancy but rather to the presence of synaptic AMPA receptors devoid of $\gamma 8$. Consistent with this interpretation, administration of GYKI52466 at a maximally tolerated dose (6 $\mathrm{mg} / \mathrm{kg}$, i.v.) produced a significantly greater decrease in wind up compared with LY3130481. Interestingly, this high dose of GYKI52466 did not eliminate spinal neuron responses as observed in vitro; a similar residual response has been reported for WDR neurons after administration of the nonselective AMPA receptor blockers 2,3-dioxo-6-nitro-1,2,3,4-tetrahydrobenzo[f]quinoxaline-7-sulfonamide (NBQX) and 6-cyano7-nitroquinoxaline-2,3-dione (CNQX) (Dougherty et al., 1992), suggesting either incomplete occupancy of AMPA receptors and/or activation of other receptor subtypes (e.g., kainate) in vivo.

Although the present in vivo studies focused on LY3130481 modulation of glutamatergic signaling in spinal cord, previous studies have demonstrated a role for potentiation in the ACC in pain conditions (Bliss et al., 2016). Indeed, mechanical allodynia produced by peripheral nerve injury has been linked to AMPA receptor-dependent synaptic potentiation in ACC, whereas suppression of injury-induced potentiation is associated with an attenuation of allodynia ( $\mathrm{Li}$ et al., 2010). These findings suggest that effects of LY3130481 on glutamate signaling and behavioral function after injury may be conferred at both spinal and supraspinal nociceptive regions of the CNS expressing $\gamma 8$-containing AMPA receptors.

LY3130481 Modulates Behavioral Responses to Injury. The hypothesis for LY3130481 to have a wider therapeutic window in chronic pain rests on its molecular selectivity combined with the localized distribution of $\gamma 8$ subunits in CNS 
A

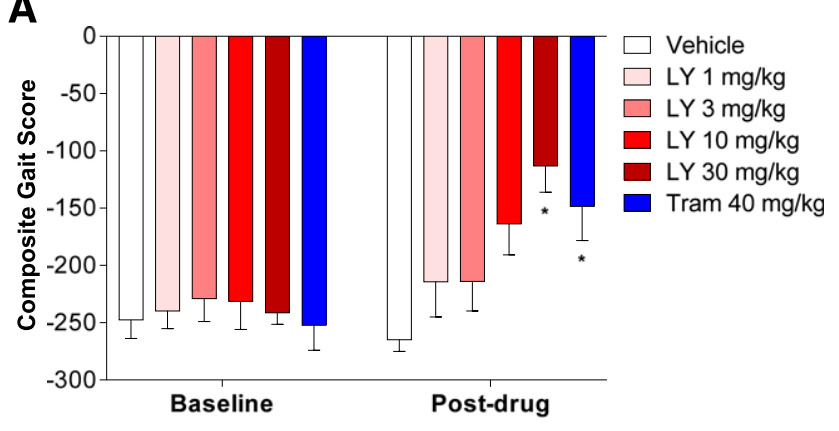

B

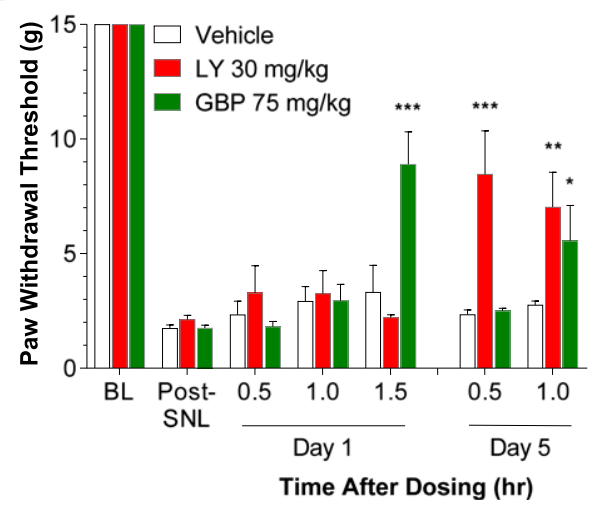

Fig. 12. LY3130481 attenuates CFA-induced gait deficits and tactile allodynia after spinal nerve ligation in rats. (A) Intra-articular CFA administration produced profound gait impairment in female SpragueDawley rats, leading to the avoidance of weight bearing during forced ambulation (baseline, 2 days post CFA). Oral administration of LY3130481 (1-30 mg/kg) dose-dependently attenuated gait deficits when administered 3 days post CFA, as measured by the composite gait score. Tramadol (40 mg/kg, PO) also significantly reduced deficits in gait. Bars represent means \pm S.E.M.s, $n=8$ animals per group; $* P<0.05$ vs. vehicle. (B) Ligation of the L5 and L6 spinal nerves produces a marked decrease in the withdrawal threshold (tactile allodynia) of the injured hindpaw as measured by probing with graded von Frey filaments. Administration of gabapentin (GBP, $75 \mathrm{mg} / \mathrm{kg}, \mathrm{PO})$ reversed tactile allodynia on both day 1 and day 5 of dosing. In contrast, LY3130481 (30 mg/kg, PO) had no effect after 1 day of dosing but did produce a significant reversal of tactile allodynia after 5 days of dosing. Data are expressed as response (grams), gram force applied to the hindpaw ipsilateral to the ligation. Bars represent mean \pm S.E.M. withdrawal thresholds. $* P<0.05 ; * * P<0.01$; $* * * P<0.001$, mean S.E., p 0.05 compared with vehicle; \#, p 0.1 compared with vehicle. $\mathrm{BL}$, baseline.

and their fractional expression in synaptic AMPA receptors in pain pathways. The present studies demonstrated that LY3130481 partially reduces nociceptive signaling in CNS and attenuates nocifensive behaviors in rodents following formalin-induced tissue injury, which increases c-fiber discharge and spinal WDR neuron activity. The magnitude of the behavioral effects were positively correlated with occupancy of $\gamma 8$-AMPA receptors in CNS and abrogated in $\gamma 8^{-1-}$ mice, confirming the $\gamma 8$ dependence of the antinociceptive action. As importantly, the effects of LY3130481 were evident in the absence of CNS side effects (Kato et al., 2016). By contrast, the suppressive effects of GYKI52466 on formalin-induced behaviors were associated with ataxia and sedation, and neither the antinociceptive nor side effects were eliminated in $\gamma 8^{-/-}$mice. These results indicate that blockade of $\gamma 8$-containing AMPA receptors or other AMPA receptors can reduce nocifensive behaviors, but that the gross CNS side effects are likely dependent on AMPA receptors not assembled with $\gamma 8$.
TARP $\gamma 2$ subunits are expressed in the dorsal horn (Larsson et al., 2013; Sullivan et al., 2017) and appear to be critical for translocation of calcium-permeable AMPA receptors at c-fiber synapses after CFA-induced peripheral inflammation (Sullivan et al., 2017), suggesting an alternative substrate for the GYKI52466 antinociception in $\gamma 8^{-1-}$ mice. Although the behavioral consequences of these $\gamma 2$-dependent changes have not been explored, GYKI52466 can suppress CFA-induced behaviors, possibly through blockade of $\gamma 2$-containing AMPA receptors (Park et al., 2008). However, blockade of $\gamma 2$-containing AMPA receptors would be expected to have concomitant motor impairment due to the high levels of expression of $\gamma 2$ subunits in the cerebellum (Tomita et al., 2003), a hypothesis supported by the severe motor abnormalities associated with $\gamma 2$ deletion (Chen et al., 2000). Collectively, these data predict that blockade of multiple subtypes of AMPA receptor complexes may confer analgesia, and the motor impairment may be dependent on $\gamma 2$-containing AMPA receptors.

The present studies also showed that LY3130481 markedly improved the composite gait score in rats after joint injury induced CFA. Examination of video recordings clearly showed that joint injury rendered animals lame, and that use of the affected hindpaw during ambulation was rescued by LY3130481 treatment. Similar results have been described for clinically efficacious compounds (e.g., anti-nerve growth factor (NGF) antibody) in chronic pain disorders, including those involving joint damage (Lane et al., 2010). Additional studies showed that LY3130481 was effective in reversing tactile allodynia produced by spinal nerve ligation after 5 days, but not 1 day, of dosing. These latter findings demonstrate the ability of $\gamma 8$-AMPA antagonism to rescue a behavioral deficit after an injury has been established for multiple weeks. In addition, the data suggest that such efficacy may require sustained $\gamma 8$-AMPA receptor blockade to modify the longerlasting plasticity mechanisms in glutamatergic nociceptive pathways that have been previously described (Latremoliere and Woolf, 2009).

Given the high expression in the hippocampus, an obvious concern of blocking $\gamma 8$-containing AMPA receptors is disturbances in cognitive function. Recent preclinical studies have specifically addressed this possibility by testing LY3130481 in several orthogonal measures of cognitive function (Witkin et al., 2017a). Results from behavioral experiments were equivocal such that LY3130481 produced impairment in some but not all assays, and topiramate, which impacts cognitive function in humans (Wandschneider et al., 2017), was without effect in tests in which LY3130481 was impairing (Witkin et al., 2017a). Similarly, the $\gamma 8$-dependent antagonist JNJ-55511118 was recently reported to produce only minor impairments in performance in the Morris water maze, the V-maze, and in a delayed nonmatching to position task (Maher et al., 2016). In addition, electroencephalogram recordings showed that LY3130481 did not have sedative effects, but rather increased wake times and attenuated impairing effects of antiepileptic drugs. In addition, LY3130481 increased efflux of histamine and acetylcholine in the prefrontal cortex, which have been associated with procognitive effects in animals (Witkin et al., 2017a). Although these data do not refute the possibility that LY3130481 may impact cognitive function, they underscore the need to definitively determine the relationship between any analgesic signal and cognitive impairment in the clinic. 
Anticonvulsants and Analgesics. Anticonvulsant drugs have been used since the 1960s in pain management (Rockliff and Davis, 1966; McQuay, 1995). These drugs can have one or more mechanisms of action (Bialer, 2012), including modulation of GABAergic and glutamatergic neurotransmission and/ or alteration of sodium, calcium, or potassium ion channels (Rogawski and Loscher, 2004), each of which has the ability to dampen the aberrant hyperexcitability of neuronal circuits associated with seizures (Bialer, 2012). We recently demonstrated that LY3130481 can suppress seizure activity in hippocampal circuits and have marked anticonvulsant effects in multiple preclinical models of seizure (Kato et al., 2016; Witkin et al., 2017b). A similar hyperexcitability in pain pathways has been described following nerve injury and is characterized by spontaneous ectopic discharge in peripheral nerves that contributes to enhanced synaptic transmission and repetitive firing of CNS neurons, which is perceived as chronic pain (Rogawski and Loscher, 2004; Bialer, 2012). The ability of LY3130481 to dampen hyperexcitable neural circuits in tissues relevant to both seizure initiation and pain signaling is consistent with clinically efficacious molecules having both analgesic and anticonvulsant properties (e.g., carbamazepine, gabapentin). Taken together, these data prompt the hypothesis that selectively targeting $\gamma 8$-containing AMPA receptors may have therapeutic potential in both seizure disorders and chronic pain conditions.

\section{Acknowledgments}

We would like to thank Caryn O'Brien for technical assistance with the autoradiography experiments.

\section{Authorship Contributions}

Participated in research design: Knopp, Nisenbaum, Need, Sher, Bredt, Felder, Burris, Barth, Reel, Ornstein, Gardinier, Simmons, Guo, Adams, Choong, Wall, Zwart, Schober, Kato, Porter, Swanson. Conducted experiments: Simmons, Guo, Adams, Choong, Wall, Zwart, Schober, Kato, Ding, Witkin, Porter, Swanson.

Contributed new reagents or analytic tools: Barth, Reel, Ornstein, Gardinier, Ding, Witkin, Gernert, Wang, Qian, Porter.

Performed data analysis: Knopp, Nisenbaum, Need, Sher, Burris, Simmons, Guo, Adams, Choong, Wall, Zwart, Schober, Kato, Catlow. Wrote or contributed to the writing of the manuscript: Knopp, Nisenbaum, Need, Sher, Bredt, Felder, Simmons, Guo, Adams, Choong, Wall, Zwart, Schober, Kato.

\section{References}

Abbott FV, Franklin KB, and Westbrook RF (1995) The formalin test: scoring properties of the first and second phases of the pain response in rats. Pain 60:91-102. Adams BL, Guo W, Gors RT, and Knopp KL (2016) Pharmacological interrogation of a rodent forced ambulation model: leveraging gait impairment as a measure of pain behavior pre-clinically. Osteoarthritis Cartilage 24:1928-1939.

Barth VN, Chernet E, Martin LJ, Need AB, Rash KS, Morin M, and Phebus LA (2006) Comparison of rat dopamine D2 receptor occupancy for a series of antipsychotic drugs measured using radiolabeled or nonlabeled raclopride tracer. Life Sci 78:3007-3012.

Baumbarger PJ, Muhlhauser M, Zhai J, Yang CR, and Nisenbaum ES (2001) Positive modulation of alpha-amino-3-hydroxy-5-methyl-4-isoxazole propionic acid (AMPA) receptors in prefrontal cortical pyramidal neurons by a novel allosteric potentiator. $J$ Pharmacol Exp Ther 298:86-102.

Bee LA and Dickenson AH (2009) Effects of lacosamide, a novel sodium channel modulator, on dorsal horn neuronal responses in a rat model of neuropathy. Neuropharmacology 57:472-479.

Bialer M (2012) Why are antiepileptic drugs used for nonepileptic conditions? Epilepsia 53 (Suppl 7):26-33.

Bliss TV, Collingridge GL, Kaang BK, and Zhuo M (2016) Synaptic plasticity in the anterior cingulate cortex in acute and chronic pain. Nat Rev Neurosci 17:485-496. Chaplan SR, Bach FW, Pogrel JW, Chung JM, and Yaksh TL (1994) Quantitative assessment of tactile allodynia in the rat paw. J Neurosci Methods 53:55-63.

Chapman V and Dickenson AH (1995) Time-related roles of excitatory amino acid receptors during persistent noxiously evoked responses of rat dorsal horn neurones. Brain Res 703:45-50.
Chen L, Chetkovich DM, Petralia RS, Sweeney NT, Kawasaki Y, Wenthold RJ, Bredt DS, and Nicoll RA (2000) Stargazin regulates synaptic targeting of AMPA receptors by two distinct mechanisms. Nature 408:936-943.

Chernet E, Martin LJ, Li D, Need AB, Barth VN, Rash KS, and Phebus LA (2005) Use of LC/MS to assess brain tracer distribution in preclinical, in vivo receptor occupancy studies: dopamine D2, serotonin 2A and NK-1 receptors as examples. Life Sci 78:340-346.

Coderre TJ, Fundytus ME, McKenna JE, Dalal S, and Melzack R (1993) The formalin test: a validation of the weighted-scores method of behavioural pain rating. Pain 54:43-50.

Coderre TJ and Melzack R (1992) The contribution of excitatory amino acids to central sensitization and persistent nociception after formalin-induced tissue injury. J Neurosci 12:3665-3670.

Davies SN and Lodge D (1987) Evidence for involvement of N-methylaspartate receptors in 'wind-up' of class 2 neurones in the dorsal horn of the rat. Brain Res 424: $402-406$.

Dickenson AH (1990) A cure for wind up: NMDA receptor antagonists as potential analgesics. Trends Pharmacol Sci 11:307-309.

Dickenson AH and Sullivan AF (1987) Evidence for a role of the NMDA receptor in the frequency dependent potentiation of deep rat dorsal horn nociceptive neurones following C fibre stimulation. Neuropharmacology 26:1235-1238.

Djouhri L, Koutsikou S, Fang X, McMullan S, and Lawson SN (2006) Spontaneous pain, both neuropathic and inflammatory, is related to frequency of spontaneous firing in intact C-fiber nociceptors. J Neurosci 26:1281-1292.

Dougherty PM, Palecek J, Paleckova V, Sorkin LS, and Willis WD (1992) The role of NMDA and non-NMDA excitatory amino acid receptors in the excitation of primate spinothalamic tract neurons by mechanical, chemical, thermal, and electrical stimuli. J Neurosci 12:3025-3041.

Eusebi F, Palma E, Amici M, and Miledi R (2009) Microtransplantation of ligandgated receptor-channels from fresh or frozen nervous tissue into Xenopus oocytes: a potent tool for expanding functional information. Prog Neurobiol 88:32-40.

Farkas S and Ono H (1995) Participation of NMDA and non-NMDA excitatory amino acid receptors in the mediation of spinal reflex potentials in rats: an in vivo study. Br J Pharmacol 114:1193-1205.

Fukaya M, Tsujita M, Yamazaki M, Kushiya E, Abe M, Akashi K, Natsume R, Kano M, Kamiya H, Watanabe M, et al. (2006) Abundant distribution of TARP gamma-8 in synaptic and extrasynaptic surface of hippocampal neurons and its major role in AMPA receptor expression on spines and dendrites. Eur J Neurosci 24:2177-2190.

Gardinier KM, Gernert DL, Porter WJ, Reel JK, Ornstein PL, Spinazze P, Stevens FC, Hahn P, Hollinshead SP, Mayhugh D, et al. (2016) Discovery of the first $\alpha$-amino-3-hydroxy-5-methyl-4-isoxazolepropionic acid (AMPA) receptor antagonist dependent upon transmembrane AMPA receptor regulatory protein (TARP)

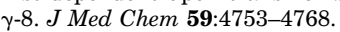

Gill MB, Kato AS, Roberts MF, Yu H, Wang H, Tomita S, and Bredt DS (2011) Cornichon-2 modulates AMPA receptor-transmembrane AMPA receptor regulatory protein assembly to dictate gating and pharmacology. J Neurosci 31: $6928-6938$.

Gill MB, Kato AS, Wang H, and Bredt DS (2012) AMPA receptor modulation by cornichon-2 dictated by transmembrane AMPA receptor regulatory protein isoform. Eur $J$ Neurosci 35:182-194.

Haley J, Ketchum S, and Dickenson A (1990) Peripheral kappa-opioid modulation of the formalin response: an electrophysiological study in the rat. Eur J Pharmacol 191:437-446.

Herrero JF, Laird JM, and López-García JA (2000) Wind-up of spinal cord neurones and pain sensation: much ado about something? Prog Neurobiol 61:169-203.

Hunter JC and Singh L (1994) Role of excitatory amino acid receptors in the mediation of the nociceptive response to formalin in the rat. Neurosci Lett 174: $217-221$.

Inamura M, Itakura M, Okamoto H, Hoka S, Mizoguchi A, Fukazawa Y, Shigemoto R, Yamamori S, and Takahashi M (2006) Differential localization and regulation of stargazin-like protein, gamma-8 and stargazin in the plasma membrane of hippocampal and cortical neurons. Neurosci Res 55:45-53.

Jackson AC and Nicoll RA (2011) The expanding social network of ionotropic glutamate receptors: TARPs and other transmembrane auxiliary subunits. Neuron $\mathbf{7 0}$ : 178-199.

Kato AS, Burris KD, Gardinier KM, Gernert DL, Porter WJ, Reel J, Ding C, Tu Y, Schober DA, Lee MR, et al. (2016) Forebrain-selective AMPA-receptor antagonism guided by TARP $\gamma-8$ as an antiepileptic mechanism. Nat Med 22:1496-1501.

Kato AS, Gill MB, Ho MT, Yu H, Tu Y, Siuda ER, Wang H, Qian YW, Nisenbaum ES, Tomita S, et al. (2010) Hippocampal AMPA receptor gating controlled by both TARP and cornichon proteins. Neuron 68:1082-1096.

Kato AS and Witkin JM (2018) Auxiliary subunits of AMPA receptors: the discovery of a forebrain-selective antagonist, LY3130481/CERC-611. Biochem Pharmacol 147:191-200.

Kim SH and Chung JM (1992) An experimental model for peripheral neuropathy produced by segmental spinal nerve ligation in the rat. Pain 50:355-363.

Lane NE, Schnitzer TJ, Birbara CA, Mokhtarani M, Shelton DL, Smith MD, and Brown MT (2010) Tanezumab for the treatment of pain from osteoarthritis of the knee. N Engl J Med 363:1521-1531.

Larsson M, Agalave N, Watanabe M, and Svensson CI (2013) Distribution of transmembrane AMPA receptor regulatory protein (TARP) isoforms in the rat spinal cord. Neuroscience 248:180-193.

Latremoliere A and Woolf CJ (2009) Central sensitization: a generator of pain hypersensitivity by central neural plasticity. J Pain 10:895-926.

Lee MR, Gardinier KM, Gernert DL, Schober DA, Wright RA, Wang H, Qian Y, Witkin JM, Nisenbaum ES, and Kato AS (2017) Structural determinants of the $\gamma-8$ TARP dependent AMPA receptor antagonist. ACS Chem Neurosci 8:2631-2647.

Leem JW, Choi EJ, Park ES, and Paik KS (1996) N-methyl-D-aspartate (NMDA) and non-NMDA glutamate receptor antagonists differentially suppress dorsal horn neuron responses to mechanical stimuli in rats with peripheral nerve injury. Neurosci Lett 211:37-40. 
Lein ES, Hawrylycz MJ, Ao N, Ayres M, Bensinger A, Bernard A, Boe AF, Boguski MS, Brockway KS, Byrnes EJ, et al. (2007) Genome-wide atlas of gene expression in the adult mouse brain. Nature 445:168-176.

Li XY, Ko HG, Chen T, Descalzi G, Koga K, Wang H, Kim SS, Shang Y, Kwak C, Park SW, et al. (2010) Alleviating neuropathic pain hypersensitivity by inhibiting PKMzeta in the anterior cingulate cortex. Science 330:1400-1404.

Maher MP, Wu N, Ravula S, Ameriks MK, Savall BM, Liu C, Lord B, Wyatt RM Matta JA, Dugovic C, et al. (2016) Discovery and characterization of AMPA receptor modulators selective for TARP- $\gamma 8$. J Pharmacol Exp Ther 357:394-414.

McCall WD, Tanner KD, and Levine JD (1996) Formalin induces biphasic activity in C-fibers in the rat. Neurosci Lett 208:45-48.

McNamara CR, Mandel-Brehm J, Bautista DM, Siemens J, Deranian KL, Zhao M, Hayward NJ, Chong JA, Julius D, Moran MM, et al. (2007) TRPA1 mediates formalin-induced pain. Proc Natl Acad Sci USA 104:13525-13530.

McQuay HJ (1995) Pre-emptive analgesia: a systematic review of clinical studies. Ann Med 27:249-256.

Menuz K, Kerchner GA, O’Brien JL, and Nicoll RA (2009) Critical role for TARPs in early development despite broad functional redundancy. Neuropharmacology 56:22-29.

Miledi R, Eusebi F, Martínez-Torres A, Palma E, and Trettel F (2002) Expression of functional neurotransmitter receptors in Xenopus oocytes after injection of human brain membranes. Proc Natl Acad Sci USA 99:13238-13242.

Miledi R, Palma E, and Eusebi F (2006) Microtransplantation of neurotransmitter receptors from cells to Xenopus oocyte membranes: new procedure for ion channel studies. Methods Mol Biol 322:347-355.

Monyer H, Seeburg PH, and Wisden W (1991) Glutamate-operated channels: developmentally early and mature forms arise by alternative splicing. Neuron 6:799-810.

Nishiyama T, Gyermek L, Lee C, Kawasaki-Yatsugi S, and Yamaguchi T (1999) The systemically administered competitive AMPA receptor antagonist, YM872, has analgesic effects on thermal or formalin-induced pain in rats. Anesth Analg 89:1534-1537.

Olsen RW, Szamraj O, and Houser CR (1987) [3H]AMPA binding to glutamate receptor subpopulations in rat brain. Brain Res 402:243-254.

O'Neill MJ, Murray TK, Whalley K, Ward MA, Hicks CA, Woodhouse S, Osborne DJ, and Skolnick P (2004) Neurotrophic actions of the novel AMPA receptor potentiator LY404187, in rodent models of Parkinson's disease. Eur J Pharmacol 486:163-174.

Ossipov MH, Lai J, Malan TP Jr, and Porreca F (2000) Spinal and supraspinal mechanisms of neuropathic pain. Ann N Y Acad Sci 909:12-24.

Park JS, Yaster M, Guan X, Xu JT, Shih MH, Guan Y, Raja SN, and Tao YX (2008) Role of spinal cord alpha-amino-3-hydroxy-5-methyl-4-isoxazolepropionic acid receptors in complete Freund's adjuvant-induced inflammatory pain. Mol Pain 4:67.

Rockliff BW and Davis EH (1966) Controlled sequential trials of carbamazepine in trigeminal neuralgia. Arch Neurol 15:129-136.

Rogawski MA and Löscher W (2004) The neurobiology of antiepileptic drugs for the treatment of nonepileptic conditions. Nat Med 10:685-692.

Rouach N, Byrd K, Petralia RS, Elias GM, Adesnik H, Tomita S, Karimzadegan S, Kealey C, Bredt DS, and Nicoll RA (2005) TARP gamma-8 controls hippocampal AMPA receptor number, distribution and synaptic plasticity. Nat Neurosci 8 1525-1533.

Schuelert N, Zhang C, Mogg AJ, Broad LM, Hepburn DL, Nisenbaum ES, Johnson MP, and McDougall JJ (2010) Paradoxical effects of the cannabinoid CB2 receptor agonist GW405833 on rat osteoarthritic knee joint pain. Osteoarthritis Cartilage 18:1536-1543.

Schwenk J, Harmel N, Brechet A, Zolles G, Berkefeld H, Müller CS, Bildl W, Baehrens D, Hüber B, Kulik A, et al. (2012) High-resolution proteomics unravel architecture and molecular diversity of native AMPA receptor complexes. Neuron 74:621-633.
Schwenk J, Harmel N, Zolles G, Bildl W, Kulik A, Heimrich B, Chisaka O, Jonas P, Schulte U, Fakler B, et al. (2009) Functional proteomics identify cornichon proteins as auxiliary subunits of AMPA receptors. Science 323:1313-1319.

Simmons RM, Forster B, Guo W, and Knopp KL (2014) A method to enhance the magnitude of tactile hypersensitivity following spinal nerve ligation in rats. $J$ Neurosci Methods 233:50-53.

Simmons RM, Li DL, Hoo KH, Deverill M, Ornstein PL, and Iyengar S (1998) Kainate GluR5 receptor subtype mediates the nociceptive response to formalin in the rat. Neuropharmacology 37:25-36.

Sommer B, Keinänen K, Verdoorn TA, Wisden W, Burnashev N, Herb A, Köhler M Takagi T, Sakmann B, and Seeburg PH (1990) Flip and flop: a cell-specific functional switch in glutamate-operated channels of the CNS. Science 249:1580-1585.

Stanfa LC and Dickenson AH (1999) The role of non-N-methyl-D-aspartate ionotropic glutamate receptors in the spinal transmission of nociception in normal animals and animals with carrageenan inflammation. Neuroscience 93:1391-1398.

Sullivan SJ, Farrant M, and Cull-Candy SG (2017) TARP $\gamma-2$ is required for inflammation-associated AMPA receptor plasticity within lamina II of the spinal cord dorsal horn. J Neurosci 37:6007-6020

Svendsen F, Tjølsen A, and Hole K (1998) AMPA and NMDA receptor-dependent spinal LTP after nociceptive tetanic stimulation. Neuroreport 9:1185-1190.

Tomita S, Chen L, Kawasaki Y, Petralia RS, Wenthold RJ, Nicoll RA, and Bredt DS (2003) Functional studies and distribution define a family of transmembrane AMPA receptor regulatory proteins. J Cell Biol 161:805-816.

Wall PD and Woolf CJ (1984) Muscle but not cutaneous C-afferent input produces prolonged increases in the excitability of the flexion reflex in the rat. J Physiol $\mathbf{3 5 6}$ $443-458$.

Wandschneider B, Burdett J, Townsend L, Hill A, Thompson PJ, Duncan JS, and Koepp MJ (2017) Effect of topiramate and zonisamide on fMRI cognitive networks. Neurology 88:1165-1171.

Wheeler-Aceto H, Porreca F, and Cowan A (1990) The rat paw formalin test: comparison of noxious agents. Pain 40:229-238.

Witkin JM, Li J, Gilmour G, Mitchell SN, Carter G, Gleason SD, Seidel WF, Eastwood BJ, McCarthy A, Porter WJ, et al. (2017a) Electroencephalographic, cognitive, and neurochemical effects of LY3130481 (CERC-611), a selective antagonist of TARP- $\gamma 8$-associated AMPA receptors. Neuropharmacology 126:257-270.

Witkin JM, Schober DA, Gleason SD, Catlow JT, Porter WJ, Reel J, Jin X, Hobbs J, Gehlert D, Gernert DL, et al. (2017b) Targeted blockade of TARP- $\gamma 8$-associated AMPA receptors: anticonvulsant activity with the selective antagonist LY3130481 (CERC-611). CNS Neurol Disord Drug Targets 16:1099-1110.

Woolf CJ and Thompson SW (1991) The induction and maintenance of central sensitization is dependent on N-methyl-D-aspartic acid receptor activation; implications for the treatment of post-injury pain hypersensitivity states. Pain 44: 293-299.

Yoshimura M and Jessell T (1990) Amino acid-mediated EPSPs at primary afferent synapses with substantia gelatinosa neurones in the rat spinal cord. J Physiol 430: 315-335.

Zhou Q, Wang J, Zhang X, Zeng L, Wang L, and Jiang W (2013) Effect of metabotropic glutamate 5 receptor antagonists on morphine efficacy and tolerance in rats with neuropathic pain. Eur J Pharmacol 718:17-23.

Address correspondence to: Kelly L. Knopp, Eli Lilly \& Company, Lilly Research Laboratories, Lilly Corporate Center, Drop Code 0510, Indianapolis, IN 46285. E-mail: k.knopp@lilly.com 